Article

\title{
A Synthetic Cytokinin Improves Photosynthesis in Rice under Drought Stress by Modulating the Abundance of Proteins Related to Stomatal Conductance, Chlorophyll Contents, and Rubisco Activity
}

\author{
Ranjit Singh Gujjar ${ }^{1,2} \mathbb{D}$, Pennapa Banyen ${ }^{1}$, Wannisa Chuekong ${ }^{1}$, Phapawee Worakan ${ }^{1}$, \\ Sittiruk Roytrakul ${ }^{3}($ i) and Kanyaratt Supaibulwatana $1, *$ (D) \\ 1 Faculty of Science, Mahidol University, Rama VI Rd., Ratchathewi, Bangkok 10400, Thailand; \\ ranjit.gujjar@icar.gov.in (R.S.G.); pennapa.by@gmail.com (P.B.); wannisa.chue@gmail.com (W.C.); \\ phapawee.w@gmail.com (P.W.) \\ 2 Division of Crop Improvement, Indian Institute of Sugarcane Research, Lucknow 226002, India \\ 3 National Center for Genetic Engineering and Biotechnology, National Science and Technology Development \\ Agency, Pathum Thani 12120, Thailand; sittiruk@biotec.or.th \\ * Correspondence: kanyaratt.sup@mahidol.ac.th
}

Received: 7 August 2020; Accepted: 24 August 2020; Published: 27 August 2020

check for updates

\begin{abstract}
Drought susceptible rice cultivar PTT1 (Pathumthani1) was treated with drought (-72 kPa) and CPPU (N-2-(chloro-4-pyridyl)-N-phenyl urea) @ $5 \mathrm{mg} / \mathrm{L}$ at tillering and grain-filling stages. Plants were tested for the effect of synthetic cytokinin on the parameters influencing the process of photosynthesis. Exogenous spray of CPPU improved the stomatal conductance of rice leaves, which was severely reduced by drought. The abundance intensities of proteins, associated with the stomatal conductance (ZEP, NCED4, PYL9, PYL10, ABI5, SnRK4, Phot1, and Phot2), were also in agreement with the positive impact of CPPU on the stomatal conductance under drought stress. Among the photosynthetic pigments, $\mathrm{Chl} b$ contents were significantly reduced by drought stress, whereas CPPU treated plants retained the normal contents of $\mathrm{Chl} b$ under drought stress. Subsequently, we examined the abundance intensities of chlorophyll synthase and HCR proteins, implicated in the biosynthesis of chlorophyll pigments and the conversion of $\mathrm{Chl} \mathrm{b}$ to $\mathrm{Chl} a$, respectively. The results indicated a drought-mediated suppression of chlorophyll synthase. However, CPPU treated plants retained normal levels of chlorophyll synthase under drought stress. In addition, drought stress induced HCR proteins, which might be the cause for reduced $\mathrm{Chl} b$ contents in drought stressed plants. Further, CPPU treatment helped the plants sustain photosynthesis at a normal rate under drought stress, which was comparable with well-watered plants. The results were further confirmed by examining the abundance intensities of two key proteins, RAF1 and Rubisco activase, implicated in the assembly and activation of Rubisco, respectively. CPPU treatment reversed the drought mediated suppression of these proteins at both of the growth stages of rice under drought stress. Based on the results, it can be suggested that synthetic cytokinins help the plants sustain photosynthesis at a normal rate under drought stress by positively influencing the determinants of photosynthesis at a molecular level.
\end{abstract}

Keywords: photosynthesis; proteome; cytokinin; drought; rice

\section{Introduction}

Drought stress is prominent worldwide and impairs plant growth and development by affecting several biochemical and physiological processes. Plants counter drought stresses naturally by 
triggering a complex stress signaling cascade resulting in up or down-regulation of numerous regulatory and functional genes [1,2]. ABA (Abscisic acid) is a well-established stress hormone that triggers stress signaling in plants [3,4]. The ultimate aim of a plant during drought stress is to survive with minimal metabolic processes, which results in sluggish growth. Cytokinins play diverse roles in plant development, including cell growth and differentiation [5]. Recent findings suggest the role of cytokinins in mediating cellular responses to drought acclimation [6-9]. Cytokinins work antagonistically to ABA to regulate many developmental processes in plants during stress conditions $[10,11]$. High cytokinin concentration during osmotic stress counteracts leaf senescence by redistributing the remobilized nutrients [7,12,13], improves photosynthetic efficiency [14-17], interrupts drought-induced ABA responses [18,19], and eventually stops all those events that guide the plant to survive with minimal resources. There is ample evidence to suggest that cytokinins help in sustaining better plant growth under osmotic stress conditions, ultimately leading to improved yield [9,15,20-22].

Exogenous applications of synthetic cytokinins during osmotic stress improve MSI (membrane stability index), photosynthetic pigments, chlorophyll stability index, leaf RWC (relative water content), leaf soluble sugars, and many other growth-related parameters [23-26]. Furthermore, exogenous cytokinin spray ameliorates oxidative stresses by increasing the activities of antioxidant enzymes [24,26] and suppresses ABA-induced stomatal closure [27,28] during drought stress. Foliar spray of CPPU/Forchlorfenuron, a phenyl urea-based synthetic cytokinin, has been widely used in recent times for exogenous cytokinin treatment. CPPU acts as a competitive inhibitor of cytokinin oxidase/dehydrogenase (CKX), which allows plants to retain higher concentrations of cytokinin [29,30]. CPPU has also been implicated in increasing the weight and size of fruit and vegetable crops [31-35]. CPPU treatment in papaya promoted drought resistance by enhancing chlorophyll contents and antioxidant activities under drought stress conditions [36]. Our previous studies showed that the application of $5 \mathrm{mg} / \mathrm{L} \mathrm{CPPU} \mathrm{promoted} \mathrm{lateral} \mathrm{branching,} \mathrm{enhanced} \mathrm{sugar} \mathrm{contents,} \mathrm{and} \mathrm{the} \mathrm{production}$ of andrographolide compounds in a medicinal plant, Andrographis paniculata [37]. Another study proved that foliar spray of CPPU enhanced the salt tolerance in rice by maintaining the rate of photosynthesis, soluble sugars, and free proline concentration under salinity stress [16]. In the context of enhanced photosynthetic ability displayed by different crop plants in response to synthetic cytokinins, we have unraveled the cytokinin mediated proteomic changes corresponding to the process of photosynthesis. The rate of photosynthesis is directly influenced by stomatal conductance that ensures the availability of $\mathrm{CO}_{2}$ and the contents of chlorophyll pigments to harvest light energy. Henceforth, the present research focuses on investigating the effect of external cytokinin spray on stomatal conductance, photosynthetic pigments, and finally the rate of photosynthesis at two different growth stages of rice plants under drought stress. To investigate the corresponding alterations at a molecular level, we also examined the abundance intensities of proteins associated with the above-mentioned determinants of photosynthesis.

\section{Materials and Methods}

\subsection{Plant Material, CPPU and Drought Stress Treatments}

Oryza sativa ssp. Indica cv. PTT1 seeds were procured from the Laboratory of Plant Physiology and Agri-biotechnology, Faculty of Science, Mahidol University, Bangkok. PTT1 is a drought sensitive cultivar of rice [38]. The seeds were disinfected by sodium hypochlorite (Chlorox ${ }^{\circledR} 10 \% v / v$ ) for $30 \mathrm{~min}$ in a $100 \mathrm{~mL}$ flask, and were subsequently germinated in a container on moistened filter paper (Whatman ${ }^{\circledR}$ no. 1) for 14 days in light at room temperature. Thirty seedlings $(5 \mathrm{~cm}$ long, with true leaves) were transplanted with the spacing of $5 \times 5$ inch into the experimental blocks (length $x$ width $x$ height $=3 \mathrm{~m} \times 2 \mathrm{~m} \times 30 \mathrm{~cm}$ ) filled with sand and soil (2:1) at the greenhouse, Salaya Campus, Mahidol University. Experimental blocks were supplemented with working Yoshida solution regularly to balance essential nutrient contents. Tensiometers (Soil Moisture, USA) were installed in the experimental blocks to keep a check on the soil moisture tension. Drought treatment was 
executed by withholding water for 14 days, whereas sufficient soil moisture (soil moisture tension was $-15 \mathrm{kPa}$ ) was maintained for control well-watered plants. Synthetic cytokinin treatment was given exogenously by foliar spraying the plants with a $5 \mathrm{mg} \mathrm{L}^{-1}$ solution of CPPU (Kyowa Hakko Kogyo Co., Ltd.) at the rate of $25 \mathrm{~mL} /$ plant [37]. CPPU solution was added with $0.1 \%$ Tween $20^{\circledR}$ that was used as a leaf surfactant. Control plants were sprayed with sterile water added with $0.1 \%$ Tween $20^{\circledR}$ solution at the same time. Plants were sprayed with the CPPU solution only once on day 6 of drought stress (soil moisture tension $-55 \mathrm{kPa}$ ). Samples were collected in three biological replicates to examine morphological, physiological, and biochemical changes on day 7 (soil moisture tension $-60 \mathrm{kPa}$ ) and day 14 (soil moisture tension $-72 \mathrm{kPa}$ ) of the drought stress treatment. A total of three treatments were used in the experiment: 1. Well-watered (WW) plants, 2. Drought stressed (DR) plants, and 3. Drought stressed plants with $5 \mathrm{mg} / \mathrm{L} \mathrm{CPPU} \mathrm{(DR-CPPU).} \mathrm{The} \mathrm{experiments} \mathrm{were} \mathrm{conducted} \mathrm{separately} \mathrm{during}$ two different growth stages of rice viz. tillering stage (60 days after germination) and grain-filling stage (75 days after germination). All the physiological, biochemical, and proteomic investigations were conducted on flag leaves with three biological replications.

\subsection{Analysis of Stomatal Conductance and Net Photosynthetic Rate}

The net photosynthetic rate $\left(\mu \mathrm{mol} \mathrm{m} \mathrm{m}^{-2} \mathrm{~s}^{-1}\right)$ and stomatal conductance $\left(\mathrm{mmol} \mathrm{m} \mathrm{m}^{-2} \mathrm{~s}^{-1}\right)$ were measured in flag leaves using a LI-6400XT Portable Photosynthesis System (LI-COR Biosciences). Measurements were taken in biological triplicates during late morning hours (10:30-11:30) using the following reference IRGA (infrared gas analyzer) chamber settings: $\mathrm{CO}_{2}$ Mixer: $\mathrm{CO}_{2} \mathrm{R}=400 \mu \mathrm{mL}$, Coolers: Tblock $=28.0^{\circ} \mathrm{C}$, Flow: Fixed $=500 \mu \mathrm{mol} \mathrm{s}^{-1}$, Lamp: ParIn $=1000 \mu \mathrm{mL}$.

\subsection{Spectrophotometric Analysis of Photosynthetic Pigments}

Photosynthetic pigments (chlorophyll a and chlorophyll $\mathrm{b}$ and total carotenoids) were analyzed in biological triplicates according to the method of Wellburn [39]. About $0.1 \mathrm{~g}$ of fresh flag leaf sample was cut into pieces and homogenized with $5 \mathrm{~mL}$ of $80 \%$ acetone and kept at $4{ }^{\circ} \mathrm{C}$ for $48 \mathrm{~h}$. The extract was filtered through a Whatman ${ }^{\circledR}$ filter paper into a separate test tube. One $\mathrm{mL}$ of filtered extract was used for spectrophotometric determination (GENESYS ${ }^{\mathrm{TM}}$ 10S UV-Vis Spectrophotometer) of Chl a (chlorophyll a), Chl b (chlorophyll b), and carotenoids at 663, 645, and $470 \mathrm{~nm}$ absorbance, respectively. The quantification of $\mathrm{Chl} a, \mathrm{Chl} \mathrm{b}$, and carotenoids was performed by the following standard equations: chlorophyll $\mathrm{a}=12.7 \mathrm{~A}_{663}-2.69 \mathrm{~A}_{645}$, chlorophyll $\mathrm{b}=22.9 \mathrm{~A}_{645}-4.68 \mathrm{~A}_{663}$, carotenoids $=\left(1000 \mathrm{~A}_{470}-2.270 \mathrm{Chl} \mathrm{a}-81.4 \mathrm{Chl} \mathrm{b}\right) / 227$. The results were expressed as micrograms of chlorophylls or carotenoids per gram of fresh leaf tissue $\left(\mu \mathrm{g} \mathrm{g}^{-1}\right)$.

\subsection{Protein Extraction and Sample Preparation for Shotgun Proteomics}

Fresh flag leaf samples were collected in triplicates (biological) from all of the treatment combinations of drought and CPPU for differential proteomic analysis. Proteins were extracted using a modified version of the protocol described by Shen [40]. Briefly, $100 \mathrm{mg}$ of tissue was ground to a fine powder in liquid nitrogen and homogenized in pre-cooled $1 \mathrm{~mL}$ TCA extraction buffer $(10 \%$ TCA in $100 \%$ acetone added with $0.07 \%$ fresh 2 -mercaptoethanol). Samples were vortexed, incubated at $-20{ }^{\circ} \mathrm{C}$ for $1 \mathrm{~h}$, and centrifuged at $12,000 \mathrm{rpm}$ for $5 \mathrm{~min}$ at $4{ }^{\circ} \mathrm{C}$. Supernatants were discarded and precipitates were washed three times with ice-cold acetone solution (acetone containing $0.07 \%$ 2-mercaptoethanol). The precipitates were dried in the oven at $55^{\circ} \mathrm{C}$ for $30 \mathrm{~min}$, dissolved with a lysis buffer (30 mM Tris-base (Tris hydroxymethyl aminomethane), $7 \mathrm{M}$ urea, $2 \mathrm{M}$ thiourea, $4 \%$ CHAPS, $\mathrm{pH} 8.5$ ), and vortexed and centrifuged at $12,000 \mathrm{rpm}$ for $15 \mathrm{~min}$. Supernatants containing crude protein mixtures were collected after centrifugation and stored at $-20^{\circ} \mathrm{C}$. The concentration of proteins was measured using BSA (bovine serum albumin) as a standard protein [41] and absorbance was taken by Microplate Reader-TECAN (Spark 10M) at $595 \mathrm{~nm} .10 \mu \mathrm{g}$ protein samples from each biological triplicate were mixed for further LC-MS analysis. To reduce the disulfide bond, $10 \mathrm{mM}$ dithiothreitol in $10 \mathrm{mM}$ ammonium bicarbonate was added to the protein solution and reformation of disulfide bonds in 
the proteins was blocked by alkylation with $30 \mathrm{mM}$ iodoacetamide in $10 \mathrm{mM}$ ammonium bicarbonate. The protein samples were digested with sequencing grade porcine trypsin (1:20 ratio) for $16 \mathrm{~h}$ at $37^{\circ} \mathrm{C}$. The tryptic peptides were dried using a speed vacuum concentrator and re-suspended in $0.1 \%$ formic acid for nano-liquid chromatography-tandem mass spectrometry (nanoLC-MSMS) analysis.

\subsection{Liquid Chromatography-Tandem Mass Spectrometry (LC/MS) and Data Analysis}

Tryptic peptide samples were injected in triplicate into a HCTUltra LC-MS system (Bruker Daltonics Ltd.; Hamburg, Germany), coupled with a nanoLC system: UltiMate 3000 LC System (Thermo Fisher Scientific; Madison, WI, USA) as well as an electrospray at the flow rate of $300 \mathrm{~nL}-\mathrm{min}^{-1}$ to a nanocolumn (PepSwift monolithic column $100 \mathrm{~mm}$ internal diameter $50 \mathrm{~mm}$ ). Mobile phases consisting of solvent A ( $0.1 \%$ formic acid) and solvent B ( $80 \%$ acetonitrile and $0.1 \%$ formic acid) were used to elute peptides using a linear gradient of $10-70 \%$ of solvent $B$ at $0-13 \mathrm{~min}$ (the time-point of retention), followed by $90 \% \mathrm{~B}$ at $13-15 \mathrm{~min}$ to transfer all peptides in the column. The final elution of $10 \% \mathrm{~B}$ at $15-20 \mathrm{~min}$ was carried out at the end to remove any remaining salt. The quantitation of LC-MSMS data was performed by Differential Analysis software (DeCyderMS, GE Healthcare) [42,43], and the identification of proteins was performed by searching against the Oryza sativa non-redundant subset database of the National Center for Biotechnology Information (NCBI). The mass spectrometry proteomics data have been deposited to the ProteomeXchange Consortium via the PRIDE [1] partner repository with the dataset identifier PXD021005. Searches were performed with a maximum of three missed cleavages, carbamidomethylation of Cys as a fixed modification, and oxidation of Met as variable modifications. Protein scores were derived from ion scores as a nonprobabilistic ranking protein hits and obtained as the sum of peptide scores. Data normalization and the quantification of the changes in protein abundance were performed among different treatments by MultiExperiment Viewer $(\mathrm{MeV})$ in the TM4 suite software [44]. The relative abundance of peptides was presented as $\log 2$ abundance intensities. The highest $\log 2$ abundance intensity value among the three technical replicates was used as the representative value of that treatment.

\section{Results and Discussion}

\subsection{Synthetic Cytokinins Improve Stomatal Conductance during Drought Stress}

Stomata are the environmentally controlled gateways in the plants for $\mathrm{CO}_{2}$ uptake and transpiration, and therefore play a vital role in determining the rate of photosynthesis [45]. In response to water deficit stress, plants need to meticulously balance the $\mathrm{CO}_{2}$ uptake and water transpiration through the stomatal aperture. Like various other stress induced adaptations, plants under drought stress conventionally follow the strategy to reduce the water loss through transpiration by closing stomatal apertures [46]. Cytokinins at high concentrations have been reported to revert the ABA-induced stomatal closure $[27,28]$ during abiotic stresses. In our study, we evaluated the effect of externally applied synthetic cytokinin on the stomatal conductance under drought stress (Figure 1).

There was an obvious effect of drought stress on the stomatal closure, leading to reduced conductance at both tillering and grain-filling stages. Conversely, the well-watered plants maintained a healthy stomatal conductance. However, CPPU had a noticeable impact of on stomatal conductance under drought stress, whereby the stomatal conductance of CPPU treated plants was significantly higher than that of the untreated plants, with an exception on day 14 at tillering stage.

In order to authenticate the effect of drought and CPPU on stomatal conductance, we investigated the abundance intensities of the proteins (immediately extracted from the same tissues) that were either directly or indirectly related to the stomatal conductance. During drought stress, ABA concentration and signaling plays a vital role in controlling the stomatal conductance. ABA is synthesized in the roots and leaves, and transported to the guard cells via ATP-binding cassette (ABC) transporters that are located in the plasma membrane [46]. After reaching the guard cells, ABA and its signaling components modulate the ion channel activities including the efflux of anions and potassium ions and the inhibition 
of $\mathrm{K}^{+}$import that leads to the closure of stomata [47]. To examine the involvement of ABA and its signaling components in controlling the stomatal conductance under drought stress, we evaluated the abundance intensities of some important proteins that regulate the biosynthesis and degradation of ABA. Zeaxanthin epoxidase (ZEP) and 9-cis-epoxycarotenoid dioxygenase (NCED) proteins are implicated in the biosynthesis of ABA [48], whereas Abscisic acid 8'-hydroxylase is responsible for the oxidative degradation of ABA [49]. In our study, both the proteins involved in ABA biosynthesis, ZEP and NCED, were relatively more abundant in the drought stressed plants at both day 7 and 14 of drought stress (Figure 2). In contrast, the CPPU treated plants under drought stress retained the normal levels of NCED proteins, similar to well-watered plants. However, the abundance of ZEP in synthetic cytokinin treated plants looked similar to the levels in drought stressed plants at the tillering stage. Abscisic acid $8^{\prime}$-hydroxylase protein, on the other hand, had equal abundance in all the treatments during both the growth stages of the rice. The results suggest that the treatment of synthetic cytokinin helped the plants to confine the drought induced biosynthesis of ABA and thereby facilitated the improved stomatal conductance. Further, the degradation of ABA was not swayed by either the drought or the synthetic cytokinin treatment.
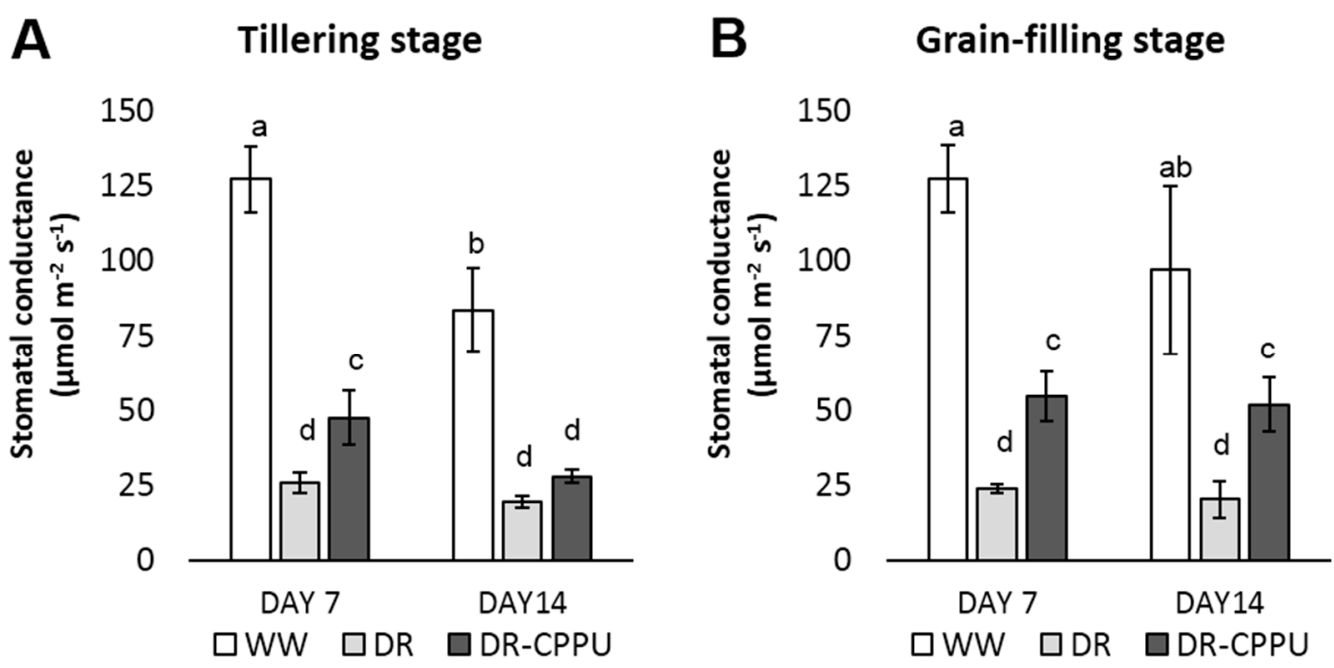

Figure 1. Stomatal conductance $\left(\mathrm{mmol} \mathrm{m}^{-2} \mathrm{~s}^{-1}\right)$ of rice leaves under different treatment conditions at tillering (A) and grain-filling (B) stages. WW = Well-watered plants (soil moisture tension of $-15 \mathrm{kPa}$ ), $\mathrm{DR}=$ Drought stressed plants (Soil moisture tension of $-55 \mathrm{kPa}$ and $-72 \mathrm{kPa}$ at day 7 and day 14 , respectively), and DR-CPPU $=$ Drought stressed plants, sprayed with $5 \mathrm{mg} / \mathrm{L} \mathrm{CPPU}$ on day 6 of drought treatment. Error bars represent SD (standard deviation). Letters viz. a, b, c, d, e, over SD bars indicate significant differences of mean at $p<0.05\left(^{*}\right)$, as analyzed by Duncan's Multiple Range Test (DMRT).

ABA signaling is umpired by its receptors, namely PYR/PYL/RCARs (Pyrabactin resistance/Pyrabactin-like/Regulatory components of the ABA receptor) and SnRK (Sucrose non-fermenting-1-related protein kinase) protein kinases, which phosphorylate the downstream targets and trigger the ABA-induced responses in plants. Under lesser availability of ABA, the function of SnRK2 is subdued by PP2C (Protein phosphatase type-2C) phosphatases, which act as negative regulators of $\mathrm{ABA}$ signaling. When the concentration is higher, $\mathrm{ABA}$ binds to its receptors, which in turn bind to PP2Cs and inactivate them. Consequently, PP2Cs are dissociated from SnRK2s, resulting in the activation of SnRK2s to initiate ABA-induced responses [3,50,51]. The ABA receptors, PYL9 and PYL10, have been independently reported for their roles in leaf senescence, lateral root elongation [52], and drought and cold tolerance $[53,54]$. In our study, the abundance of both the receptor proteins, PYL9 and PYL10, was significantly induced under drought stress (Figure 3), and there was no effect of CPPU treatment on the abundance intensity of PYL10 under drought stress. Nevertheless, abundance of PYL9 under drought stress was intimidated by CPPU treatment at both the tillering and grain-filling 
stages of the rice. The results revealed a robust drought inducible character of both PYL9 and PYL10 receptors. Among other downstream proteins of ABA signaling, SnRK4 and ABA insensitive (ABI) 5 showed differential abundance in response to synthetic cytokinin application under drought stress. An abundance of SnRK4 and ABI5 proteins was induced by drought stress in our study (Figure 4). However, CPPU treated plants under drought stress maintained normal abundance levels of these proteins, which was comparable with well-watered plants. ABI4 and ABI5 proteins act as positive regulators of $\mathrm{ABA}$ signaling $\mathrm{ABA}$ arbitrated responses in plants [55,56]. Some other downstream proteins involved in ABA signaling like PP2C04, BIPP2C1, ABA insensitive (ABI) 4, and SnRK1 showed equal abundance in all the treatments without being influenced by drought or the CPPU treatment (Table 1).
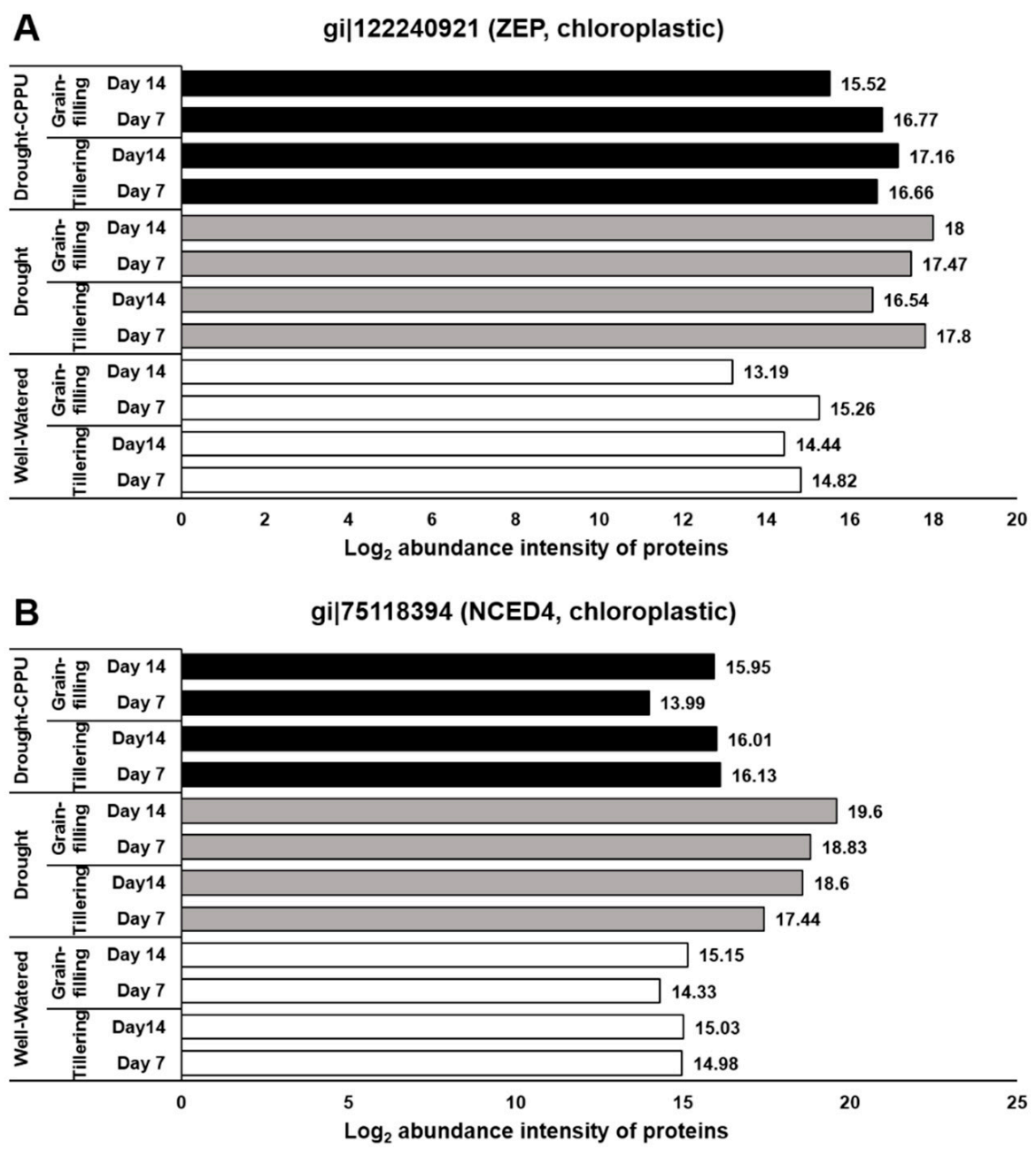

Figure 2. The influence of synthetic cytokinin and drought on the abundance intensities of ZEP (A) and NCED4 (B) proteins, implicated in ABA biosynthesis and stomatal conductance, at the tillering and grain-filling stages of the rice. Protein abundance intensities, represented on the $\mathrm{X}$-axis, are the highest $\log 2$ fold change values of technical replicates. [Well-Watered plants were maintained at a soil moisture tension of $-15 \mathrm{kPa}$ during the treatment period. Drought stress was imposed by withholding water for up to 14 days. Soil moisture tensions of $-55 \mathrm{kPa}$ and $-72 \mathrm{kPa}$ were recorded at day 7 and day 14 during the treatment, respectively. CPPU treatment was given by foliar spraying plants with a $5 \mathrm{mg} / \mathrm{L}$ solution of CPPU at the rate of $25 \mathrm{~mL} /$ plant on day 6 of drought treatment. 


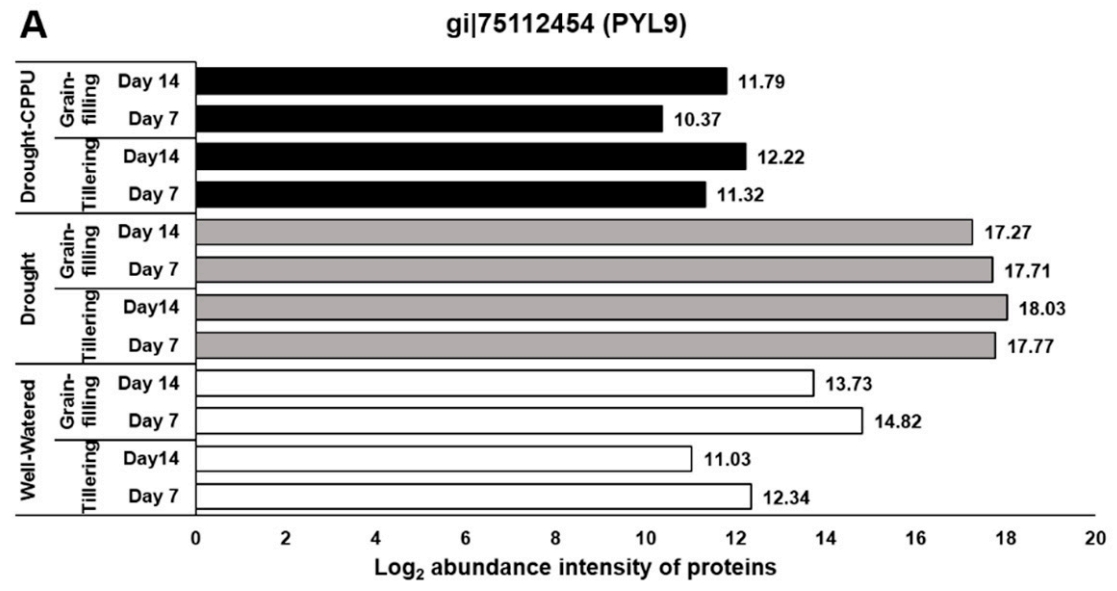

B gi|75141253 (PYL10)

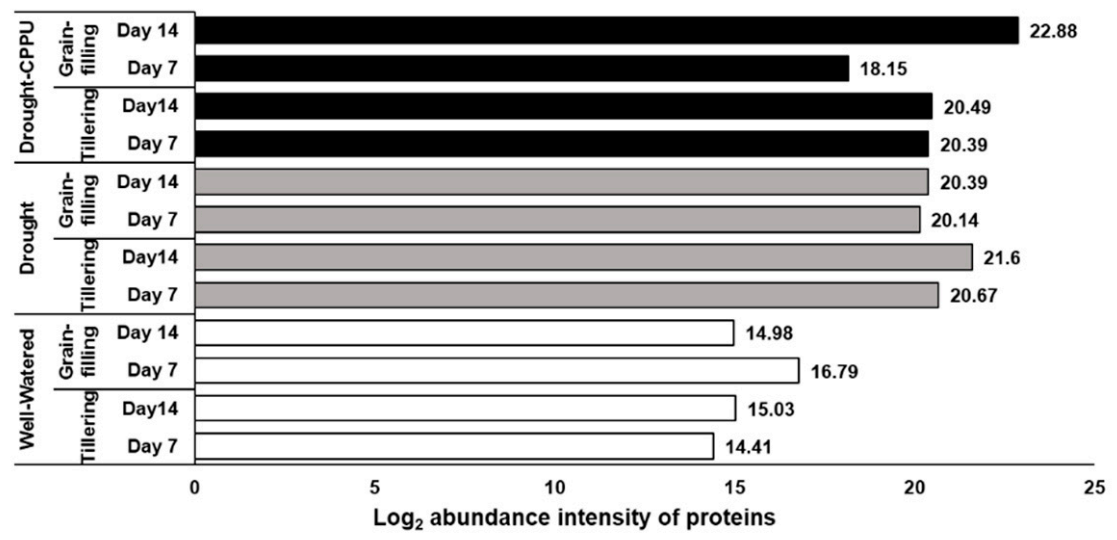

Figure 3. The influence of synthetic cytokinin and drought on the abundance intensities of PYL9 (A) and PYL10 (B) proteins, implicated in ABA reception and stomatal conductance, at the tillering and grain-filling stages of the rice. Protein abundance intensities, represented on the $X$ - axis, are the highest $\log 2$ fold change values of technical replicates. [Well-Watered plants were maintained at a soil moisture tension of $-15 \mathrm{kPa}$ during the treatment period. Drought stress was imposed by withholding water for up to 14 days. Soil moisture tensions of $-55 \mathrm{kPa}$ and $-72 \mathrm{kPa}$ were recorded at day 7 and day 14 during the treatment, respectively. CPPU treatment was given by foliar spraying plants with a $5 \mathrm{mg} / \mathrm{L}$ solution of CPPU at the rate of $25 \mathrm{~mL} /$ plant on day 6 of drought treatment.

The opening and closing of stomata is tightly regulated through various ion channels located in the guard cell membranes. During the opening of the stomata, the $\mathrm{H}^{+}$-ATPase pumps facilitate the efflux of $\mathrm{H}^{+}$from the guard cells. Extrusion of $\mathrm{H}^{+}$ions from the guard cells results in the acidification of the apoplast that leads to $\mathrm{K}^{+}$uptake via activation of inward potassium channels $[57,58]$. The potassium $\left(\mathrm{K}^{+}\right)$channels were first discovered in Arabidopsis thaliana and have been named as ATKs [59,60]. Phototropins (phot1, phot2) have been widely reported to control the stomatal opening through the activation of plasma membrane bound $\mathrm{H}^{+}$-ATPase [61]. Localized on the outer membrane of chloroplast, phototropins are the plant-specific protein kinases that act as blue light photoreceptors [62]. They regulate a wide range of physiological processes such as stomatal opening, chloroplast relocations, and phototropism (bending towards light) in order to maximize the photosynthetic efficiency [63-65]. Genetic analysis has revealed two different phototropins (Phot 1 and 2) with partially overlapping functions in plants [66]. BLUS1 (BLUe light Signaling 1), a Ser/Thr protein kinase, mediates the primary step for phototropin signaling in guard cells. Phototropins phosphorylate the Ser-348 residue within C-terminus of BLUS1 and trigger its kinase activity, which subsequently phosphorylates and activates the plasma membrane $\mathrm{H}^{+}$-ATPase, causing stomata to open [61,67]. We investigated the effect of 
CPPU on the abundance intensities of both the phototropins (Phot1 and Phot2) under drought stress (Figure 5), whereby both blue light receptor kinases were substantially intimidated by drought stress at tillering and grain-filling stages. However, CPPU treatment helped the plants retain the normal levels of these blue light receptor kinases under drought stress like the well-watered plants. Potassium channels (KAT1, 2, 5, and 6), located on the plasma membrane of guard cells, also have key roles in stomatal opening as they facilitate the inward uptake of $\mathrm{K}^{+}$ions into the guard cells $[59,60]$. In our study, we also analyzed the abundance of these potassium channel proteins (KAT1, 2, 5, and 6) under different treatments in rice. However, they remained unaffected across all of the treatments in rice (Table 1).
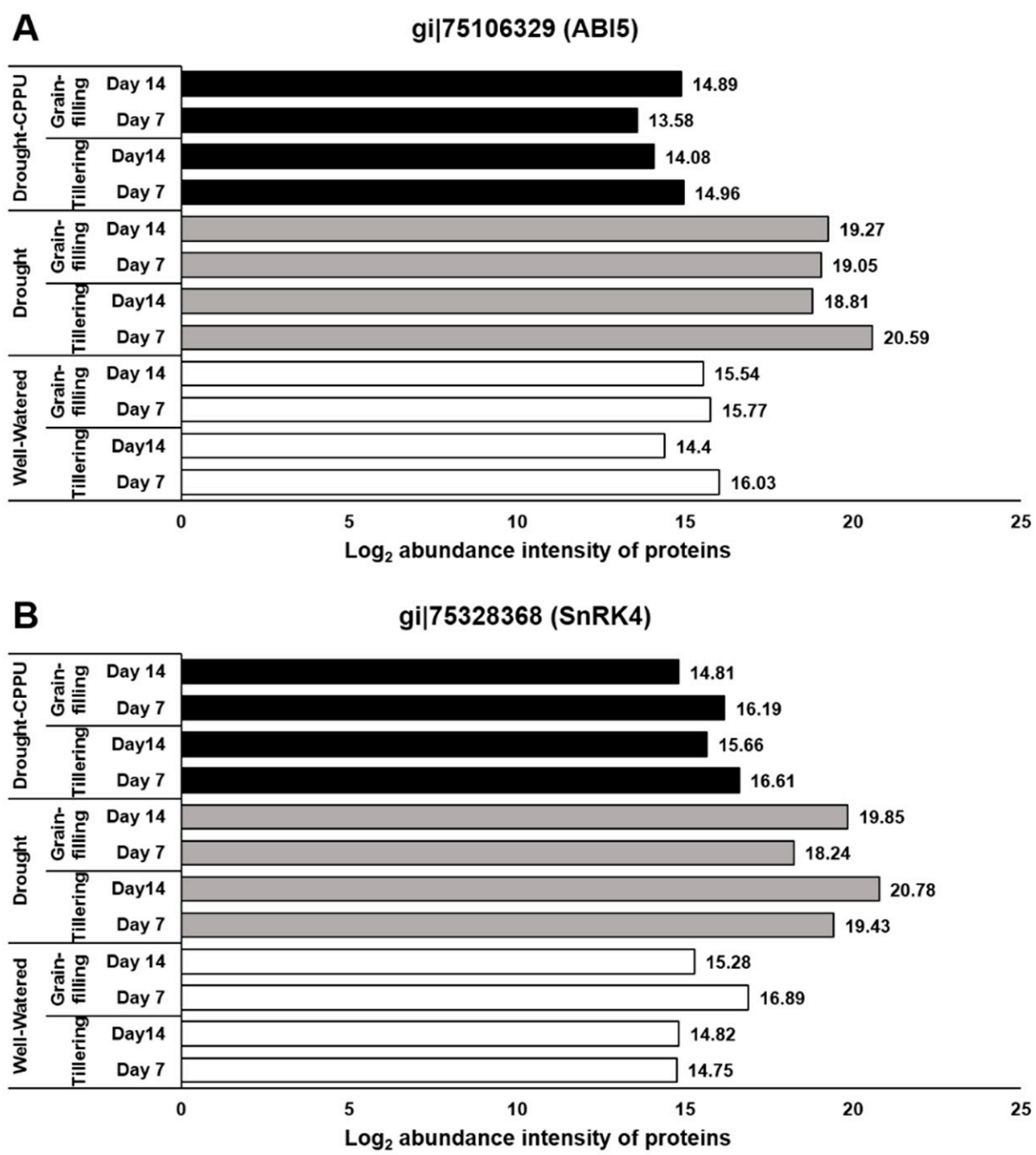

Figure 4. The influence of synthetic cytokinin and drought on the abundance intensities of ABI5 (A) and SnRK4 (B) proteins, implicated in ABA signaling and stomatal conductance, at the tillering and grain-filling stages of the rice. Protein abundance intensities, represented on the $X$ - axis, are the highest $\log 2$ fold change values of technical replicates. [Well-Watered plants were maintained at a soil moisture tension of $-15 \mathrm{kPa}$ during the treatment period. Drought stress was imposed by withholding water for up to 14 days. Soil moisture tensions of $-55 \mathrm{kPa}$ and $-72 \mathrm{kPa}$ were recorded at day 7 and day 14 during the treatment, respectively. CPPU treatment was given by foliar spraying plants with a $5 \mathrm{mg} / \mathrm{L}$ solution of CPPU at the rate of $25 \mathrm{~mL} /$ plant on day 6 of drought treatment. 
Table 1. Rice flag leaf proteins (related to stomatal conductance) with unchanged abundance intensities in different treatments. The highest $\log 2$ intensity value among the three technical replicates was used as the representative value of that treatment.

\begin{tabular}{|c|c|c|c|c|c|c|c|c|c|c|c|c|c|}
\hline \multirow{4}{*}{ GI No. } & \multirow{4}{*}{ Name of Protein } & \multicolumn{4}{|c|}{ Well-Watered $^{1}$} & \multicolumn{4}{|c|}{ Drought $^{2}$} & \multicolumn{4}{|c|}{ Drought-CPPU $^{3}$} \\
\hline & & \multicolumn{2}{|c|}{ Tillering } & \multicolumn{2}{|c|}{ Grain-filling } & \multicolumn{2}{|c|}{ Tillering } & \multicolumn{2}{|c|}{ Grain-filling } & \multicolumn{2}{|c|}{ Tillering } & \multicolumn{2}{|c|}{ Grain-filling } \\
\hline & & Day & Day & Day & Day & Day & Day & Day & Day & Day & Day & Day & Day \\
\hline & & 7 & 14 & 7 & 14 & 7 & 14 & 7 & 14 & 7 & 14 & 7 & 14 \\
\hline gi|75124964 & Potassium channel KAT1 & 16.43 & 14.47 & 14.42 & 15.89 & 15.94 & 16.13 & 15.62 & 14.27 & 14.64 & 16.22 & 16.12 & 15.45 \\
\hline gi|338810402 & Potassium channel KAT2 & 17.77 & 18.55 & 17.13 & 18.80 & 19.33 & 18.59 & 17.68 & 18.49 & 18.80 & 18.33 & 20.57 & 18.47 \\
\hline gi|75144382 & Potassium channel KAT5 & 16.90 & 18.63 & 17.25 & 17.08 & 18.90 & 17.51 & 17.83 & 17.36 & 18.25 & 17.09 & 17.11 & 16.33 \\
\hline gi|338810388 & Potassium channel KAT6 & 15.79 & 17.97 & 16.92 & 14.16 & 14.91 & 15.32 & 16.37 & 16.72 & 16.65 & 15.82 & 16.23 & 15.93 \\
\hline gi|122163981 & Abscisic acid $8^{\prime}$-hydroxylase 1 & 17.30 & 18.39 & 17.47 & 16.83 & 17.82 & 16.75 & 17.45 & 18.50 & 17.04 & 17.46 & 19.97 & 14.88 \\
\hline gi|75328369 & $\begin{array}{l}\text { Serine/threonine protein } \\
\text { kinase OSK1 SnRK1 }\end{array}$ & 15.77 & 17.39 & 17.37 & 16.38 & 17.42 & 16.84 & 16.87 & 16.80 & 17.79 & 15.73 & 15.62 & 16.53 \\
\hline gi|75222723 & $\begin{array}{c}\text { Protein kinase and PP2C-like } \\
\text { domain-containing protein } \\
\text { PP2C04 }\end{array}$ & 14.60 & 16.37 & 15.36 & 16.13 & 17.05 & 17.19 & 16.43 & 16.52 & 16.71 & 17.15 & 15.32 & 14.86 \\
\hline gi|122247433 & $\begin{array}{c}\text { Protein phosphatase 2C } \\
\text { BIPP2C1 }\end{array}$ & 16.70 & 19.26 & 16.88 & 16.48 & 17.46 & 17.21 & 17.78 & 16.50 & 18.91 & 17.80 & 18.52 & 18.68 \\
\hline gi|75123651 & Protein ABIL4 & 20.64 & 19.89 & 20.49 & 18.95 & 21.65 & 19.52 & 20.20 & 20.21 & 17.72 & 18.42 & 20.44 & 19.66 \\
\hline
\end{tabular}

${ }^{1}$ Well-watered plants were maintained at a soil moisture tension of $-15 \mathrm{kPa}$ during the treatment period. ${ }^{2}$ Drought stress was imposed by withholding water for up to 14 days. Soil moisture tensions of $-55 \mathrm{kPa}$ and $-72 \mathrm{kPa}$ were recorded at day 7 and day 14 during the treatment, respectively. ${ }^{3} \mathrm{CPPU}$ treatment was given by foliar spraying plants with a $5 \mathrm{mg} / \mathrm{L}$ solution of CPPU [N-2-(chloro-4-pyridyl)-N-phenyl urea] at the rate of $25 \mathrm{~mL} /$ plant on day 6 of drought treatment.

A

gi|122248708 (Phot-1A)

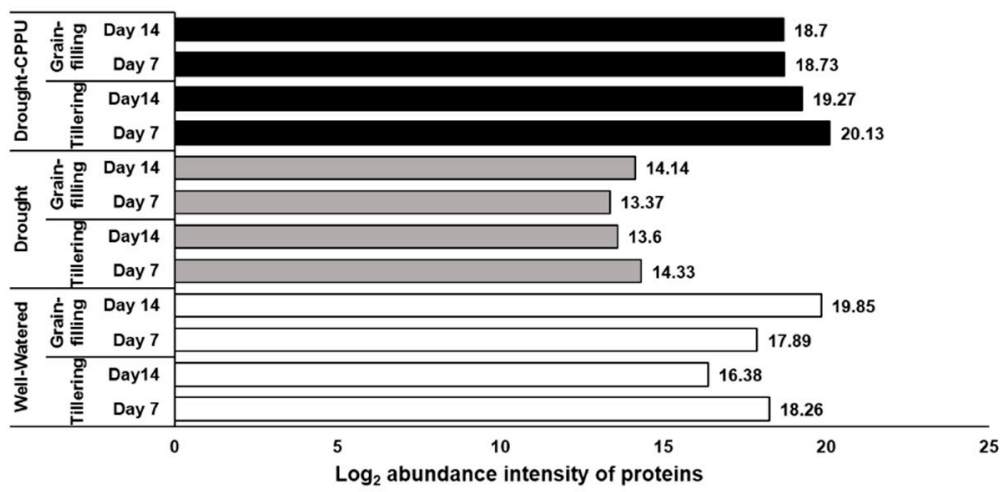

B gi|75337608 (Phot-2)

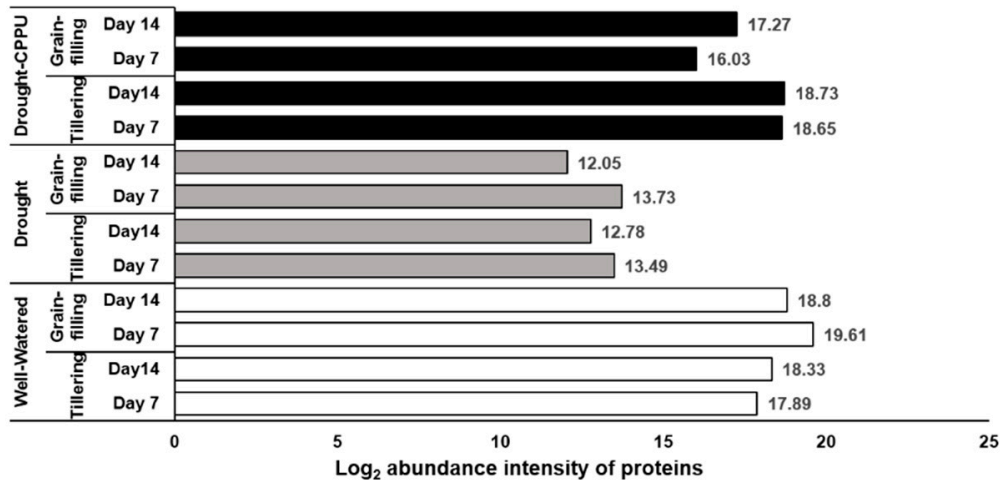

Figure 5. The influence of synthetic cytokinin and drought on the abundance intensities of phototropins, Phot-1 (A), and Phot-2 (B) proteins, implicated in photosynthesis and stomatal conductance at tillering and grain-filling stages of the rice. Protein abundance intensities, represented on the $\mathrm{X}$ - axis, are the highest $\log 2$ fold change values of technical replicates. [Well-Watered plants were maintained at a soil moisture tension of $-15 \mathrm{kPa}$ during the treatment period. Drought stress was imposed by withholding water for up to 14 days. Soil moisture tensions of $-55 \mathrm{kPa}$ and $-72 \mathrm{kPa}$ were recorded at day 7 and day 14 during the treatment, respectively. CPPU treatment was given by foliar spraying plants with a $5 \mathrm{mg} / \mathrm{L}$ solution of CPPU at the rate of $25 \mathrm{~mL} /$ plant on day 6 of drought treatment. 
In our study, the abundance intensities of proteins were not substantially influenced by the growth stages (tillering and grain-filing) of rice. Effects of drought and CPPU were predominantly noticeable on the proteins involved in ABA biosynthesis and signaling and phototropins. ABA biosynthesis and signaling proteins, indorsing stomatal closure, were induced under drought stress that might have caused stomatal closure and reduced the stomatal conductance in drought stressed plants. In contrast, CPPU treatment curtailed the effect of drought on these proteins, resulting in improved stomatal conductance under drought stress. Furthermore, phototropins (Phot1 and Phot2), implicated in stomatal opening, were suppressed by drought stress, which might have resulted in the partial closure of stomata and poor stomatal conductance in drought stressed plants. Interestingly, CPPU treated plants under drought stress retained the higher levels of phototropins, which was comparable with the well-watered plants, which might have resulted in improved stomatal conductance.

\subsection{Synthetic Cytokinins Augment Chl b and Confine Carotenoid Contents under Drought Stress}

Photosynthetic pigments are essential for plants to harvest light energy and produce reducing powers. Pigments are prone to environmental stresses, particularly drought (Farooq et al., 2009). Osmotic stresses reduce chlorophyll b contents without substantially affecting the contents of Chl a in drought stressed leaves $[68,69]$. To apprehend the influence of CPPU on photosynthetic pigments under drought stress, we quantified $\mathrm{Chl}$ a and $\mathrm{Chl} \mathrm{b}$ spectrophotometrically in drought stressed leaves of rice (Figure 6). Chl a contents were largely unaffected by either CPPU treatment or drought stress and the concentration fluctuated in a very narrow range of $26-32 \mu \mathrm{g} \mathrm{g}^{-1}$. Drought stress perpetually reduced the $\mathrm{Chl} b$ contents in the leaves at both growth stages of the rice. $\mathrm{Chl} b$ contents increased significantly in response to CPPU treatment under drought stress conditions. Interestingly, the $\mathrm{Chl} b$ content of CPPU treated plants under drought stress was higher than that in well-watered plants at day 14 in the tillering stage and at day 7 and day 14 in the grain-filling stage.
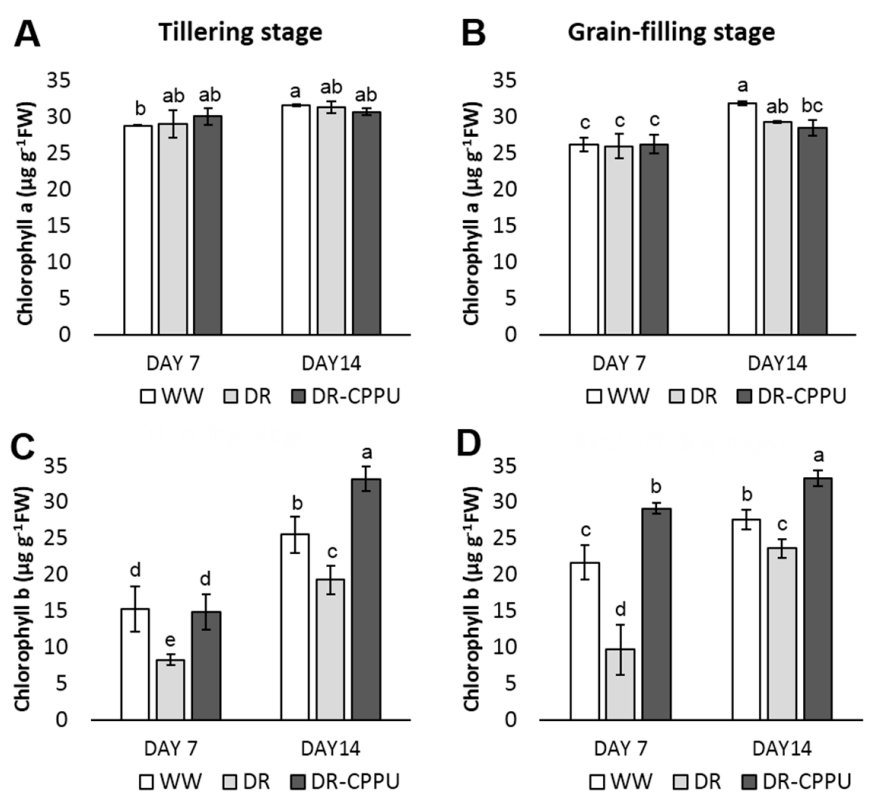

Figure 6. Contents of chlorophyll pigments $\left(\mu \mathrm{g} \mathrm{g}^{-1} \mathrm{FW}\right), \mathrm{Chl} \mathrm{a}(\mathbf{A}, \mathbf{B})$ and $\mathrm{Chl} \mathrm{b}(\mathbf{C}, \mathbf{D})$, quantified from rice leaves under different treatment conditions at tillering and grain-filling stages. WW $=$ Well-watered plants (soil moisture tension of $-15 \mathrm{kPa}$ ), DR = Drought stressed plants (Soil moisture tension of $-55 \mathrm{kPa}$ and $-72 \mathrm{kPa}$ at day 7 and day 14, respectively), and DR-CPPU = Drought stressed plants, sprayed with $5 \mathrm{mg} / \mathrm{L} \mathrm{CPPU} \mathrm{on} \mathrm{day} 6$ of drought treatment. Error bars represent SD (standard deviation). Letters viz. a, b, c, d, e, over SD bars indicate the highly significant differences of mean at $\left.p<0.01{ }^{* *}\right)$ as analyzed by Duncan's Multiple Range Test (DMRT). 
To authenticate the effect of drought and synthetic cytokinin spray on photosynthetic pigments, we investigated the abundance intensities of two key enzymes, chlorophyll synthase and 7-hydroxymethyl chlorophyll a reductase (HCAR), involved in biosynthesis/degradation of chlorophyll pigments. Chlorophyll synthase, involved in the final step of the biosynthetic pathway of chlorophylls, catalyzes the esterification of chlorophillide a or b with phytyl or geranyl-geranyl pyrophosphate into chlorophyll $\mathrm{a}$ or $\mathrm{b}$ as final product in the chloroplast $[70,71]$. Reduced expression of chlorophyll synthase also instigates a feedback-controlled inactivation of the initial and rate-limiting step of the chlorophyll synthetic pathway in plants [72]. In our study, the abundance of chlorophyll synthase protein was severely affected by the drought exposure, whereas CPPU treated plants retained sufficient levels of this enzyme under drought stress (Figure 7A). Another enzyme involved in chlorophyll metabolism, HCAR, revealed contrasting abundance patterns under drought stress (Figure 7B). It showed enhanced abundance in drought stressed leaves and relatively low abundance in well-watered and CPPU treated plants under drought stress. HCAR belongs to the iron-sulfur flavoprotein group containing FAD and an iron-sulfur center [73]. It catalyzes the reduction of a hydroxymethyl group to a methyl group and thereby converts 7-hydroxymethyl chlorophyll to chlorophyll a in the chloroplast. Interestingly, 7-hydroxymethyl chlorophyll, which serves as substrate for HCAR, is derived from the $\mathrm{NaBH}_{4}$ mediated reduction of chlorophyll $\mathrm{b}$ in the chloroplast [74]. Henceforth, HCAR has been categorized as a catabolic enzyme of the chlorophyll cycle that carries out the second and the last step in the conversion of chlorophyll $b$ to chlorophyll a [75]. Previous studies in Arabidopsis and rice indicated that HCAR-overexpressing plants exhibited accelerated leaf yellowing and senescence due to the degradation of chlorophyll $\mathrm{b}$ in the chloroplast, whereas HCAR knockout mutants exhibited persistent green leaves during both dark-induced and natural senescence [76,77]. The abundance intensities of chlorophyll synthase and HCAR proteins clearly corroborate with the results of spectrophotometrically quantified $\mathrm{Chl}$ a and $\mathrm{Chl} b$ pigments. Consequent to the reduced abundance of chlorophyll synthase, it can be hypothesized that drought stressed plants maintain the concentration of $\mathrm{Chl}$ a at the cost of $\mathrm{Chl} b$ through enhanced levels of HCAR, which actively converts $\mathrm{Chl} \mathrm{b}$ into $\mathrm{Chl}$ a. On the other hand, synthetic cytokinin treatment helps sustain the expression of chlorophyll synthase under drought stress, which in turn helps retain the contents of chlorophyll pigments (both $\mathrm{Chl}$ a and $\mathrm{Chl} \mathrm{b)} \mathrm{at} \mathrm{satisfactory} \mathrm{levels,} \mathrm{which} \mathrm{is} \mathrm{comparable} \mathrm{with} \mathrm{well-watered} \mathrm{plants.}$

Carotenoid contents tend to increase under osmotic stresses as they have additional roles during stress conditions and partially help the plants to withstand drought $[78,79]$. Total carotenoid contents were also measured spectrophotometrically in all of the treatments (Figure 8A,B). Drought stressed plants, in most cases, retained higher contents of carotenoids compared with well-watered plants. However, with the progression of drought stress, from day 7 to day 14, carotenoid contents invariably demonstrated a severe reduction in all of the treatments. However, CPPU treatment helped in moderating carotenoids contents under drought stress. To verify the influence of drought and synthetic cytokinin on the contents of total carotenoids, we investigated the abundance intensities of Carotenoid cleavage dioxygenases 8 (CCD8) in all of the treatments (Figure 8C). Carotenoid cleavage dioxygenases are responsible for the oxidative cleavage of carotenoids [80]. CCD8 in particular is involved in strigolactones biosynthesis by cleaving the C(27) 9-cis-10'-apo-beta-carotenal produced by CCD7 [81]. Strigolactones are hormones that inhibit tillering and shoot branching through the MAX-dependent pathway [82] and have been widely implicated in acclimation to environmental stresses $[83,84]$. Recent studies suggest that CRISPR/Cas9-mediated mutagenesis of CCD8 alters the root and shoot architecture and provides resistance against some parasitic weeds [85-87]. In our study, CCD8B protein was induced by CPPU during severe drought stress (day 14) at both the tillering and grain-filling stages. The results largely corroborated with the concentration of carotenoids in the synthetic cytokinin treated plant, particularly at the grain-filling stage under drought stress. Evidently, the concentration of total carotenoids was considerably less in CPPU treated plants on day 14 of drought stress at both tillering and grain-filling stages of the rice. The inclusive results of photosynthetic pigments implied the positive effect of synthetic cytokinin treatment on the total chlorophyll contents $(\mathrm{Chl} \mathrm{a}+\mathrm{Chl} b)$ 
during drought stress, which may be corroborated with the proteomic patterns where the abundance intensities of chlorophyll synthase and HCAR enzymes were meticulously controlled by synthetic cytokinin under drought stress. Furthermore, low contents of carotenoids in CPPU treated plants might be comprehended by the abundance of CCD8B enzyme in their leaves.
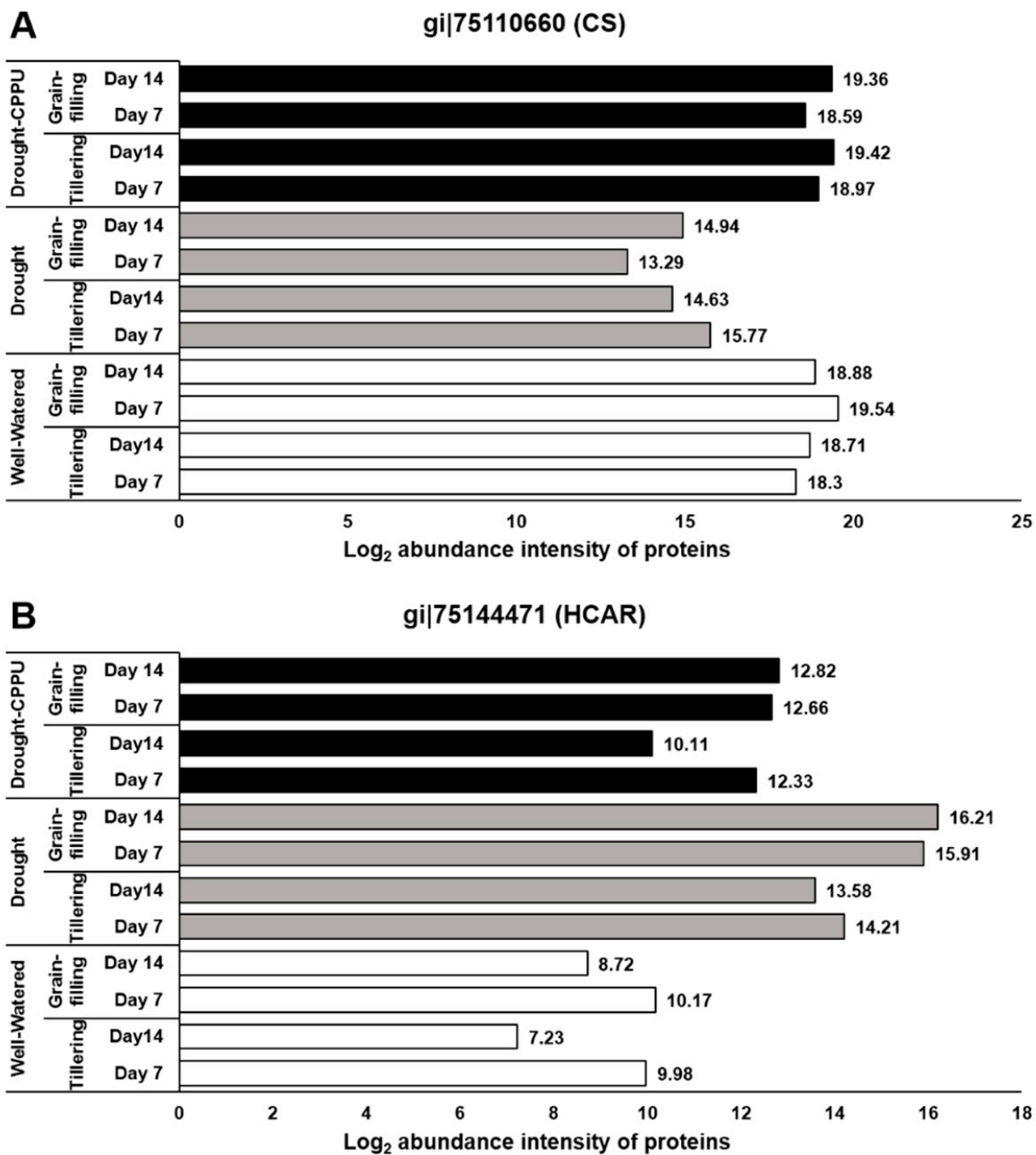

Figure 7. The influence of synthetic cytokinin and drought on the abundance intensities of (A) chlorophyll synthase (CS) and (B) 7-hydroxymethyl chlorophyll a reductase (HCAR) proteins involved in biosynthesis/degradation of chlorophyll pigments at tillering and grain-filling stages of the rice. Protein abundance intensities, represented on the $\mathrm{X}$ - axis, are the highest log2 fold change values of technical replicates. [Well-Watered plants were maintained at a soil moisture tension of $-15 \mathrm{kPa}$ during the treatment period. Drought stress was imposed by withholding water for up to 14 days. Soil moisture tensions of $-55 \mathrm{kPa}$ and $-72 \mathrm{kPa}$ were recorded at day 7 and day 14 during the treatment, respectively. CPPU treatment was given by foliar spraying plants with a $5 \mathrm{mg} / \mathrm{L}$ solution of CPPU at the rate of $25 \mathrm{~mL} /$ plant on day 6 of drought treatment. 

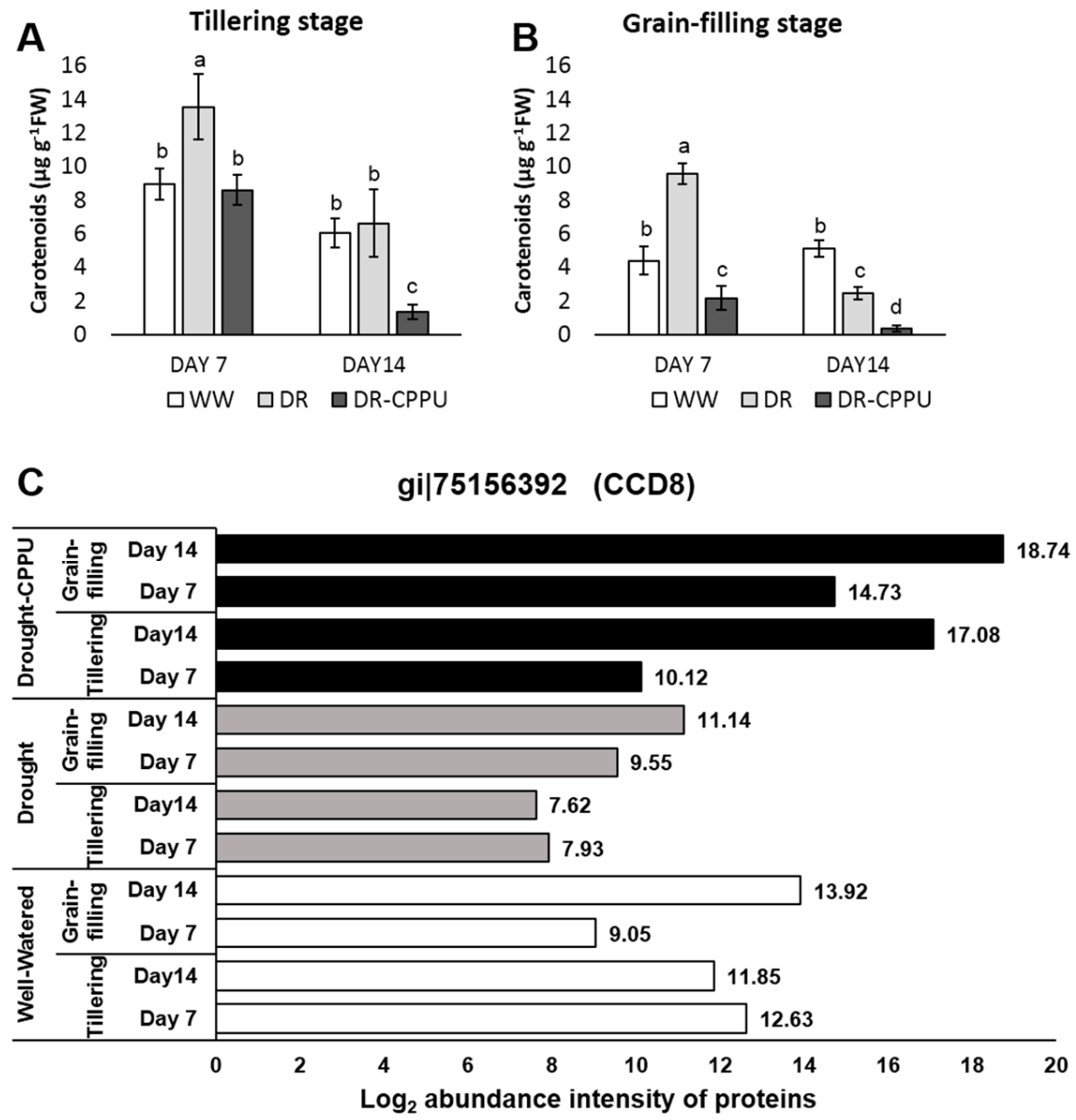

Figure 8. Total carotenoid contents $\left(\mu \mathrm{g} \mathrm{g}^{-1} \mathrm{FW}\right)$ quantified from rice leaves under different treatment conditions at tillering $(\mathbf{A})$ and grain-filling $(\mathbf{B})$ stages. $W W=$ Well-watered plants (soil moisture tension of $-15 \mathrm{kPa}$ ), DR $=$ Drought stressed plants (Soil moisture tension of $-55 \mathrm{kPa}$ and $-72 \mathrm{kPa}$ at day 7 and day 14, respectively), and DR-CPPU = Drought stressed plants, sprayed with $5 \mathrm{mg} / \mathrm{L} \mathrm{CPPU}$ on day 6 of drought treatment. Error bars represent SD (standard deviation). Letters viz. a, b, c, d, e, over SD bars indicate the highly significant differences of mean at $p<0.01\left({ }^{* *}\right)$, as analyzed by Duncan's Multiple Range Test (DMRT). (C) Influence of synthetic cytokinin and drought on the abundance intensities of the Carotenoid cleavage dioxygenases 8 (CCD8) protein involved in oxidative degradation of carotenoids at the tillering and grain-filling stages of the rice. Protein abundance intensities, represented on the X-axis, are the highest $\log 2$ fold change values of technical replicates. [Well-Watered plants were maintained at a soil moisture tension of $-15 \mathrm{kPa}$ during the treatment period. Drought stress was imposed by withholding water for up to 14 days. Soil moisture tensions of $-55 \mathrm{kPa}$ and $-72 \mathrm{kPa}$ were recorded at day 7 and day 14 during the treatment, respectively. CPPU treatment was given by foliar spraying plants with a $5 \mathrm{mg} / \mathrm{L}$ solution of CPPU at the rate of $25 \mathrm{~mL} /$ plant on day 6 of drought treatment.

\subsection{Synthetic Cytokinins Stimulate Rubisco Activity and Uphold the Rate of Photosynthesis during Drought Stress}

The rate of photosynthesis is invariably reduced under osmotic stress conditions primarily due to the closure of stomata, which hampers $\mathrm{CO}_{2}$ intake [88]. Furthermore, drought induced decline in chlorophyll pigments also accounts for the reduced rate of photosynthesis [79]. The role of externally applied synthetic cytokinins in improving the photosynthetic rate under environmental stress conditions has been reported in various crop species [14-17]. After investigating the effect of synthetic cytokinin treatment on the stomatal conductance and photosynthetic pigments during drought stress, it was pertinent to examine the cumulative effect of these factors on the rate of photosynthesis. Henceforth, 
we investigated the effect of synthetic cytokinin treatment on the net photosynthetic rate in drought stressed plants (Figure 9). The results indicated that the net photosynthetic rate was perpetually higher in well-watered plants irrespective of CPPU treatment. On the other hand, the net photosynthetic rate was drastically reduced by drought stress at both the tillering and the grain-filling stages. Nevertheless, CPPU treated plants maintained a significantly higher rate of photosynthesis compared with untreated plants under drought stress. At the tillering stage, the adverse effect of drought on photosynthesis was virtually identical on day 7 and day 14 of drought stress. On the other hand, there was a steep decrease in the rate of photosynthesis on day 14 of drought stress in the plants at the grain-filling stage.
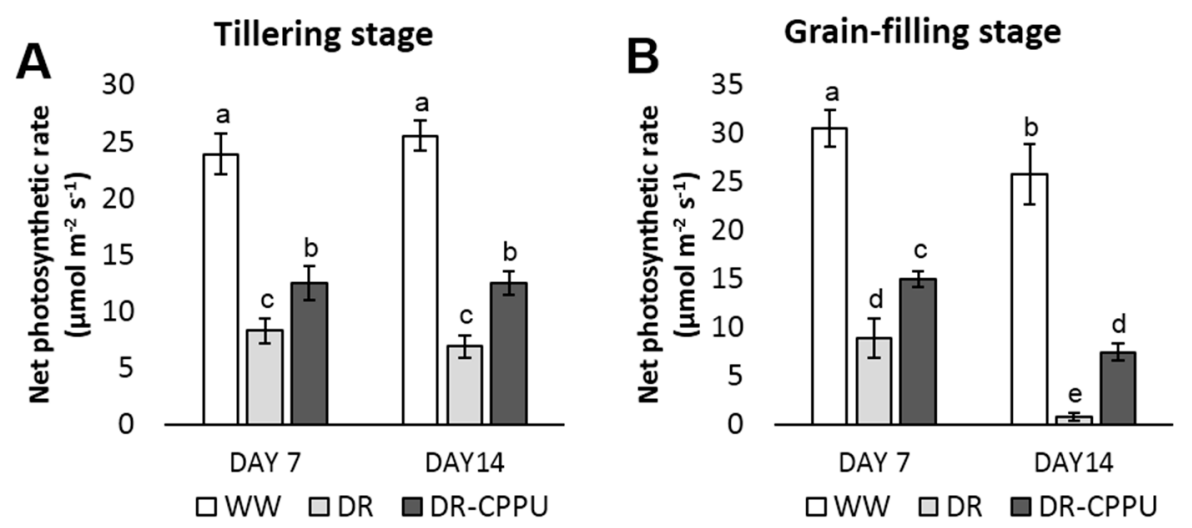

Figure 9. Net photosynthetic rate $\left(\mu \mathrm{mol} \mathrm{m}{ }^{-2} \mathrm{~s}^{-1}\right)$, measured from rice leaves under different treatment conditions at the tillering (A) and grain-filling (B) stages. WW = Well-watered plants (soil moisture tension of $-15 \mathrm{kPa}$ ), DR $=$ Drought stressed plants (Soil moisture tension of $-55 \mathrm{kPa}$ and $-72 \mathrm{kPa}$ at day 7 and day 14, respectively), and DR-CPPU = Drought stressed plants, sprayed with $5 \mathrm{mg} / \mathrm{L} \mathrm{CPPU} \mathrm{on}$ day 6 of drought treatment. Error bars represent SD (standard deviation). Letters viz. a, b, c, d, e, over SD bars indicate the highly significant differences of mean at $p<0.01\left({ }^{* *}\right)$, as analyzed by Duncan's Multiple Range Test (DMRT).

To verify the positive impact of synthetic cytokinin treatment on the process of photosynthesis under drought stress, we investigated the abundance intensities of two regulatory proteins, Rubisco accumulation factor 1 (Raf1) and Ribulose bisphos carbo/oxygenase (Rubisco) activase, required for the proper functioning of Rubisco. Rubisco, a complex of eight large (RbcL) and eight small (RbcS) subunits, is the rate-limiting carbon-fixing enzyme of photosynthesis. Rubisco activase and Raf1 are the key enzymes that regulate the activity of Rubisco and consequently the process of photosynthesis. Rubisco activase (Rca) acts as a catalytic chaperone in regulating the activity of Rubisco by facilitating the dissociation of inhibitory sugar phosphates from the active site of Rubisco in an ATP-dependent manner $[89,90]$. On the other hand, Raf1 is a key molecular chaperone, which assists the assembly of the Rubisco subunits [91,92]. Raf1 dimers facilitate the stabilization and assembly of the post-chaperonin-folded Rubisco L-subunits [93]. In our study, abundance intensities of both Rubisco activase and Raf1 proteins was intimidated by drought stress at the tillering and grain-filling stages of the rice (Figure 10). However, the synthetic cytokinin treatment helped the plants sustain the normal levels of these proteins, thereby assisting plants to uphold the rate of photosynthesis during drought stress. The synthetic cytokinin treatment also induced phototropins (Phot1 and Phot2), which are implicated in blue light reception and chloroplast translocation to assist the process of photosynthesis. 


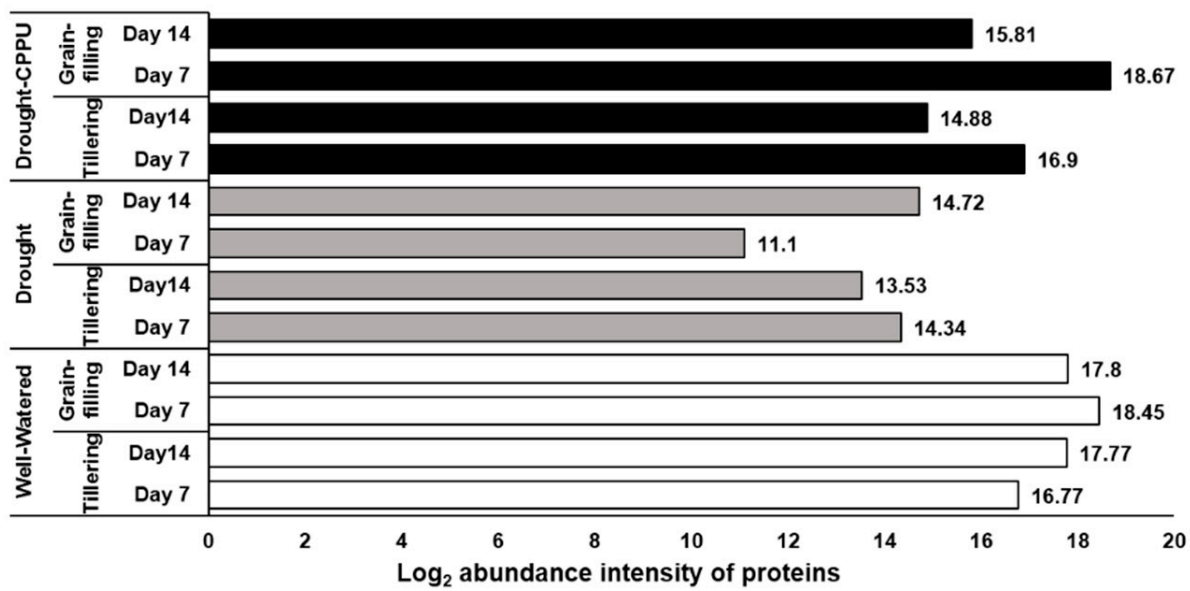

B

gi|75141498 (RAF1, chloroplastic)

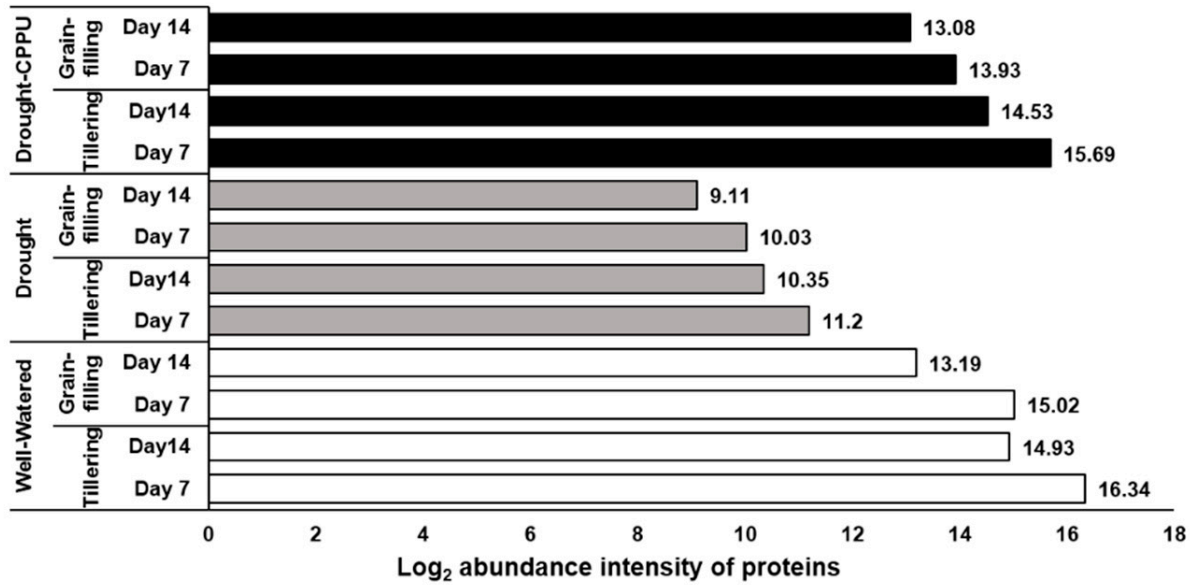

Figure 10. The influence of synthetic cytokinin and drought on the abundance intensities of (A) Ribulose bisphos carbo/oxygenase (Rubisco) activase and (B) Rubisco accumulation factor (Raf) 1 proteins involved in the regulation and functioning of Rubisco at the tillering and grain-filling stages of the rice. Protein abundance intensities, represented on the $X$ - axis, are the highest $\log 2$ fold change values of technical replicates. [Well-Watered plants were maintained at a soil moisture tension of $-15 \mathrm{kPa}$ during the treatment period. Drought stress was imposed by withholding water for up to 14 days. Soil moisture tensions of $-55 \mathrm{kPa}$ and $-72 \mathrm{kPa}$ were recorded at day 7 and day 14 during the treatment, respectively. CPPU treatment was given by foliar spraying plants with a $5 \mathrm{mg} / \mathrm{L}$ solution of CPPU at the rate of $25 \mathrm{~mL} /$ plant on day 6 of drought treatment.

\section{Conclusions}

The three major external variables that precisely control the process of photosynthesis are light, $\mathrm{CO}_{2}$, and water. Water deficit stress severely affects the rate of photosynthesis in plants, which leads to leaf wilting, reduced fresh biomass, and reduced yield. During the process of photosynthesis, the availability of $\mathrm{CO}_{2}$ is ensured by optimal stomatal conductance, whereas the photosynthetic pigments assist in harvesting the light energy. The ubiquitous enzyme, Rubisco, fixes atmospheric $\mathrm{CO}_{2}$ into the energy-rich carbon molecules. Cytokinins help plants sustain normal growth and development by positively modulating various drought induced morphological, physiological, and biochemical processes. Enhanced cytokinins in plants induce the expression of phototropins implicated in stomatal opening and curtail ABA biosynthesis and signaling, thus improving the stomatal conductance in plants during drought stress. Cytokinins control the biosynthesis of chlorophyll pigments meticulously 
by increasing the abundance of chlorophyll synthase and confining the abundance of HCAR under drought stress. Further, cytokinins modulate the expression of key proteins involved in the assembly and activation of the Rubisco enzyme, thus helping maintain the photosynthesis at a decent rate during drought stress. Conclusively, synthetic cytokinins reverse the drought induced alterations in the plants and allow normal growth and developmental activities (Figure 11). Plenty of research findings suggest that the cytokinins support normal growth and development under osmotic stresses and improve the drought tolerance ability of plants. However, the precise molecular mechanism of cytokinin mediated drought tolerance is yet to be discovered.

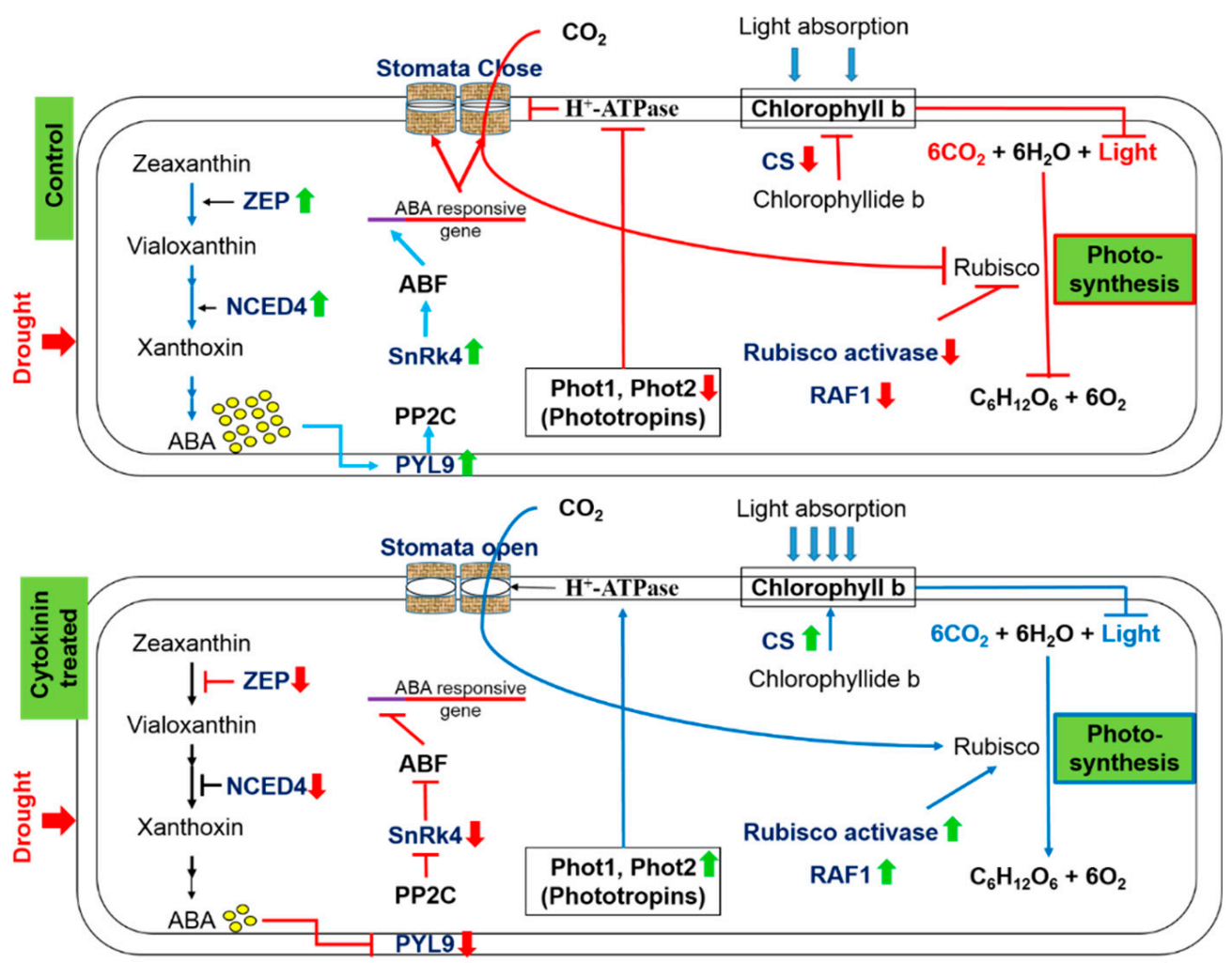

Figure 11. The positive impact of synthetic cytokinin on stomatal conductance, contents of chlorophyll $\mathrm{b}$, and the process of photosynthesis under severe drought stress. Up (green) and down (red) arrows are the symbolic representations of increase and decrease, respectively. ZEP = Zeaxanthin epoxidase, NCED = 9-cis-epoxycarotenoid dioxygenase, ABA = Abscisic acid, PYL9 = Pyrabactin-like receptor 9, PP2C = Protein phosphatase type-2C, SnRK4 = Sucrose non-fermenting-1-related protein kinase $4, \mathrm{ABF}=\mathrm{ABA}$ responsive factor, Phot $=$ Phototropin, $\mathrm{CS}=$ Chlorophyll synthase, $\mathrm{RAF} 1=$ Rubisco accumulation factor 1.

Author Contributions: All the authors have contributed in the manuscript. R.S.G. and K.S. designed the experiment. R.S.G., P.B., W.C., and P.W. performed physiological and biochemical investigations. LCMS/MS analysis and interpretation of raw proteomics expression data was performed by S.R., R.S.G., and K.S. The manuscript was prepared by R.S.G. and edited by K.S. All authors have read and agreed to the published version of the manuscript.

Funding: The research was funded by National Research Council of Thailand from 2016-2019 (Grant number: 218383) and partially by CIF grant, Faculty of Science, Mahidol University.

Acknowledgments: We thank National Research Council of Thailand (Grant number: 218383), Mahidol University and CIF grant, Faculty of Science, Mahidol University for financial support. We acknowledge M.R. Jisnuson Svasti and Faculty of Graduate Studies, Mahidol University, for comprehensively editing the language of the manuscript. The authors would like to thank Indian Council of Agricultural Research for providing a scholarship to Ranjit Singh Gujjar.

Conflicts of Interest: The authors declare no conflict of interest. 


\section{References}

1. Yamaguchi-Shinozaki, K.; Shinozaki, K. Transcriptional regulatory networks in cellular responses and tolerance to dehydration and cold stresses. Annu. Rev. Plant Biol. 2006, 57, 781-803. [CrossRef]

2. Gujjar, R.S.; Akhtar, M.; Rai, A.; Singh, M. Expression analysis of drought-induced genes in wild tomato line (Solanum habrochaites). Curr. Sci. 2014, 107, 496-502.

3. Raghavendra, A.S.; Gonugunta, V.K.; Christmann, A.; Grill, E. ABA perception and signalling. Trends Plant Sci. 2010, 15, 395-401. [CrossRef] [PubMed]

4. Gujjar, R.S.; Akhtar, M.; Singh, M. Transcription factors in abiotic stress tolerance. Indian J. Plant Physiol. 2014, 19, 306-316. [CrossRef]

5. Kieber, J.J.; Schaller, G.E. Cytokinin signaling in plant development. Development 2018, 145. [CrossRef] [PubMed]

6. Li, W.; Herrera-Estrella, L.; Tran, L.S.P. The Yin-Yang of cytokinin homeostasis and drought acclimation/adaptation. Trends Plant Sci. 2016, 21, 548-550. [CrossRef] [PubMed]

7. Xiao, X.O.; Zeng, Y.M.; Cao, B.H.; Lei, J.J.; Chen, Q.H.; Meng, C.M.; Cheng, Y.J. PSAG12-IPT overexpression in eggplant delays leaf senescence and induces abiotic stress tolerance. J. Hortic. Sci. Biotechnol. 2017, 92, 349-357. [CrossRef]

8. Xu, Y.; Huang, B. Transcriptional factors for stress signaling, oxidative protection, and protein modification in ipt-transgenic creeping bentgrass exposed to drought stress. Environ. Exp. Bot. 2017, 144, 49-60. [CrossRef]

9. Prerostova, S.; Dobrev, P.; Gaudinova, A.; Knirsch, V.; Körber, N.; Pieruschka, R.; Humplik, J. Cytokinins: Their impact on molecular and growth responses to drought stress and recovery in Arabidopsis. Front. Plant Sci. 2018, 9, 655. [CrossRef]

10. Huang, X.; Hou, L.; Meng, J.; You, H.; Li, Z.; Gong, Z.; Shi, Y. The antagonistic action of abscisic acid and cytokinin signaling mediates drought stress response in Arabidopsis. Mol. Plant 2018, 11, 970-982. [CrossRef]

11. Gujjar, R.S.; Supaibulwatana, K. The mode of cytokinin functions assisting plant adaptations to osmotic stresses. Plants 2019, 8, 542. [CrossRef] [PubMed]

12. Zhang, P.; Wang, W.Q.; Zhang, G.L.; Kaminek, M.; Dobrev, P.; Xu, J.; Gruissem, W. Senescence-inducible expression of isopentenyl transferase extends leaf life, increases drought stress resistance and alters cytokinin metabolism in cassava. J. Integr. Plant Biol. 2010, 52, 653-669. [CrossRef] [PubMed]

13. Xu, Y.; Burgess, P.; Zhang, X.; Huang, B. Enhancing cytokinin synthesis by overexpressing ipt alleviated drought inhibition of root growth through activating ROS-scavenging systems in Agrostis stolonifera. J. Exp. Bot. 2016, 67, 1979-1992. [CrossRef] [PubMed]

14. Rivero, R.M.; Kojima, M.; Gepstein, A.; Sakakibara, H.; Mittler, R.; Gepstein, S.; Blumwald, E. Delayed leaf senescence induces extreme drought tolerance in a flowering plant. Proc. Natl. Acad. Sci. USA 2007, 104, 19631-19636. [CrossRef]

15. Qin, H.; Gu, Q.; Zhang, J.; Sun, L.; Kuppu, S.; Zhang, Y.; Zhang, H. Regulated expression of an isopentenyltransferase gene (IPT) in peanut significantly improves drought tolerance and increases yield under field conditions. Plant Cell Physiol. 2011, 52, 1904-1914. [CrossRef]

16. Gashaw, A.; Theerawitaya, C.; Samphumphuang, T.; Cha-um, S.; Supaibulwatana, K. CPPU elevates photosynthetic abilities, growth performances and yield traits in salt stressed rice (Oryza sativa L. spp. indica) via free proline and sugar accumulation. Pestic. Biochem. Physiol. 2014, 108, 27-33. [CrossRef]

17. Hönig, M.; Plíhalová, L.; Husičková, A.; Nisler, J.; Doležal, K. Role of cytokinins in senescence, antioxidant defence and photosynthesis. Int. J. Mol. Sci. 2018, 19, 4045. [CrossRef]

18. Ghanem, M.E.; Albacete, A.; Smigocki, A.C.; Frébort, I.; Pospíšilová, H.; Martínez-Andújar, C.; Pérez-Alfocea, F. Root-synthesized cytokinins improve shoot growth and fruit yield in salinized tomato (Solanum lycopersicum L.) plants. J. Exp. Bot. 2010, 62, 125-140. [CrossRef]

19. Wang, Y.; Li, L.; Ye, T.; Zhao, S.; Liu, Z.; Feng, Y.Q.; Wu, Y. Cytokinin antagonizes ABA suppression to seed germination of Arabidopsis by downregulating ABI5 expression. Plant J. 2011, 68, 249-261. [CrossRef]

20. Rubio-Wilhelmi, M.M.; Sanchez-Rodriguez, E.; Rosales, M.A.; Begona, B.; Rios, J.J.; Romero, L.; Ruiz, J.M. Effect of cytokinins on oxidative stress in tobacco plants under nitrogen deficiency. Environ. Exp. Bot. 2011, 72, 167-173. [CrossRef] 
21. Yang, D.; Li, Y.; Shi, Y.; Cui, Z.; Luo, Y.; Zheng, M.; Wang, Z. Exogenous cytokinins increase grain yield of winter wheat cultivars by improving stay-green characteristics under heat stress. PLOS ONE 2016, 11, e0155437. [CrossRef]

22. Joshi, R.; Sahoo, K.K.; Tripathi, A.K.; Kumar, R.; Gupta, B.K.; Pareek, A.; Singla-Pareek, S.L. Knockdown of an inflorescence meristem-specific cytokinin oxidase-OsCKX2 in rice reduces yield penalty under salinity stress condition. Plant Cell Environ. 2018, 41, 936-946. [CrossRef] [PubMed]

23. Nagar, S.H.; Arora, A.J.; Singh, V.P.; Ramakrishnan, S.; Umesh, D.K.; Kumar, S.H.; Saini, R.P. Effect of cytokinin analogues on cytokinin metabolism and stress responsive genes under osmotic stress in wheat. Bioscan 2015, 10, 67-72.

24. Chang, Z.; Liu, Y.; Dong, H.; Teng, K.; Han, L.; Zhang, X. Effects of cytokinin and nitrogen on drought tolerance of creeping bentgrass. PLoS ONE 2016, 11, e0154005. [CrossRef] [PubMed]

25. Kumari, S.; Kumar, S.; Prakash, P. Exogenous application of cytokinin (6-BAP) ameliorates the adverse effect of combined drought and high temperature stress in wheat seedling. J. Pharmacogn. Phytochem. 2018, 7, 1176-1180.

26. Samea-Andabjadid, S.; Ghassemi-Golezani, K.; Nasrollahzadeh, S.; Najafi, N. Exogenous salicylic acid and cytokinin alter sugar accumulation, antioxidants and membrane stability of faba bean. Acta Biol. Hung. 2018, 69, 86-96. [CrossRef]

27. Blackman, P.G.; Davies, W.J. The effects of cytokinins and ABA on stomatal behaviour of maize and Commelina. J. Exp. Bot. 1983, 34, 1619-1626. [CrossRef]

28. Pospíšilová, J. Interaction of cytokinins and abscisic acid during regulation of stomatal opening in bean leaves. Photosynthetica 2003, 41, 49-56. [CrossRef]

29. Kopečný, D.; Briozzo, P.; Popelková, H.; Šebela, M.; Končitíková, R.; Spíchal, L.; Houba-Hérin, N. Phenyl-and benzylurea cytokinins as competitive inhibitors of cytokinin oxidase/dehydrogenase: A structural study. Biochimie 2010, 92, 1052-1062. [CrossRef]

30. Nisler, J.; Kopečný, D.; Končitíková, R.; Zatloukal, M.; Bazgier, V.; Berka, K.; Spíchal, L. Novel thidiazuron-derived inhibitors of cytokinin oxidase/dehydrogenase. Plant Mol. Biol. 2016, 92, 235-248. [CrossRef]

31. Zabadal, T.J.; Bukovac, M.J. Effect of CPPU on fruit development of selected seedless and seeded grape cultivars. HortScience 2006, 41, 154-157. [CrossRef]

32. Kim, J.G.; Takami, Y.; Mizugami, T.; Beppu, K.; Fukuda, T.; Kataoka, I. CPPU application on size and quality of hardy kiwifruit. Sci. Hortic. 2006, 110, 219-222. [CrossRef]

33. Niu, Q.; Wang, T.; Li, J.; Yang, Q.; Qian, M.; Teng, Y. Effects of exogenous application of GA 4+ 7 and $\mathrm{N}$-(2-chloro-4-pyridyl)-N'-phenylurea on induced parthenocarpy and fruit quality in Pyrus pyrifolia 'Cuiguan'. Plant Growth Regul. 2015, 76, 251-258. [CrossRef]

34. Ainalidou, A.; Karamanoli, K.; Menkissoglu-Spiroudi, U.; Diamantidis, G.; Matsi, T. CPPU treatment and pollination: Their combined effect on kiwifruit growth and quality. Sci. Hortic. 2015, 193, 147-154. [CrossRef]

35. Qian, C.; Ren, N.; Wang, J.; Xu, Q.; Chen, X.; Qi, X. Effects of exogenous application of CPPU, NAA and GA4+ 7 on parthenocarpy and fruit quality in cucumber (Cucumis sativus L.). Food Chem. 2018, 243, 410-413. [CrossRef] [PubMed]

36. Jianchang, H.; Yan, X.; Chunxiang, Z.; Hongbin, L. Protective effect of CPPU in papaya plant under drought stress. J. Fruit Sci. 2003, 20, 211-213.

37. Worakan, P.; Karaket, N.; Maneejantra, N.; Supaibulwatana, K. A phenylurea cytokinin, CPPU, elevated reducing sugar and correlated to andrographolide contents in leaves of Andrographis paniculata (Burm. F.) Wall. Ex Nees. Appl. Biochem. Biotechnol. 2017, 181, 638-649. [CrossRef]

38. Yooyongwech, S.; Cha-um, S.; Supaibulwatana, K. Water relation and aquaporin genes (PIP1; 2 and PIP2; 1$)$ expression at the reproductive stage of rice (Oryza sativa L. spp. indica) mutant subjected to water deficit stress. Plant Omics 2013, 6, 79.

39. Wellburn, A.R. The spectral determination of chlorophylls a and $b$, as well as total carotenoids, using various solvents with spectrophotometers of different resolution. J. Plant Physiol. 1994, 144, 307-313. [CrossRef]

40. Shen, L.; Wang, X.; Wang, Z.; Wu, Y.; Chen, J. Studies on tea protein extraction using alkaline and enzyme methods. Food Chem. 2008, 107, 929-938. [CrossRef]

41. Lowry, O.H.; Rosebrough, N.J.; Farr, A.L.; Randall, R.J. Protein measurement with the Folin phenol reagent. Biol. Chem. 1951, 193, 265-275. 
42. Johansson, C.; Samskog, J.; Sundström, L.; Wadensten, H.; Björkesten, L.; Flensburg, J. Differential expression analysis of Escherichia coli proteins using a novel software for relative quantitation of LC-MS/MS data. Proteomics 2006, 6, 4475-4485. [CrossRef] [PubMed]

43. Thorsell, A.; Portelius, E.; Blennow, K.; Westman-Brinkmalm, A. Evaluation of sample fractionation using micro-scale liquid-phase isoelectric focusing on mass spectrometric identification and quantitation of proteins in a SILAC experiment. Rapid Commun. Mass Spectrom. 2007, 21, 771-778. [CrossRef]

44. Howe, E.A.; Sinha, R.; Schlauch, D.; Quackenbush, J. RNA-Seq analysis in MeV. Bioinformatics 2011, 27, 3209-3210. [CrossRef] [PubMed]

45. Farooq, M.; Wahid, A.; Kobayashi, N.; Fujita, D.; Basra, S.M.A. Plant drought stress: Effects, mechanisms and management. In Sustainable Agriculture; Springer: Dordrecht, Germany, 2009; pp. 153-188.

46. Munemasa, S.; Hauser, F.; Park, J.; Waadt, R.; Brandt, B.; Schroeder, J.I. Mechanisms of abscisic acid-mediated control of stomatal aperture. Curr. Opin. Plant Biol. 2015, 28, 154-162. [CrossRef]

47. Daszkowska-Golec, A.; Szarejko, I. Open or close the gate-stomata action under the control of phytohormones in drought stress conditions. Front. Plant Sci. 2013, 4, 138. [CrossRef] [PubMed]

48. Seo, M.; Koshiba, T. Complex regulation of ABA biosynthesis in plants. Trends Plant Sci. 2002, 7, 41-48. [CrossRef]

49. Saito, S.; Hirai, N.; Matsumoto, C.; Ohigashi, H.; Ohta, D.; Sakata, K.; Mizutani, M. Arabidopsis CYP707As encode (+)-abscisic acid 8' -hydroxylase, a key enzyme in the oxidative catabolism of abscisic acid. Plant Physiol. 2004, 134, 1439-1449. [CrossRef] [PubMed]

50. Danquah, A.; de Zelicourt, A.; Colcombet, J.; Hirt, H. The role of ABA and MAPK signaling pathways in plant abiotic stress responses. Biotechnol. Adv. 2014, 32, 40-52. [CrossRef]

51. Ullah, A.; Manghwar, H.; Shaban, M.; Khan, A.H.; Akbar, A.; Ali, U.; Fahad, S. Phytohormones enhanced drought tolerance in plants: A coping strategy. Environ. Sci. Pollut. Res. 2018, 25, 33103-33118. [CrossRef]

52. Xing, L.; Zhao, Y.; Gao, J.; Xiang, C.; Zhu, J.K. The ABA receptor PYL9 together with PYL8 plays an important role in regulating lateral root growth. Sci. Rep. 2016, 6, 27177. [CrossRef]

53. Zhao, Y.; Chan, Z.; Gao, J.; Xing, L.; Cao, M.; Yu, C.; Zhu, J.K. ABA receptor PYL9 promotes drought resistance and leaf senescence. Proc. Natl. Acad. Sci. USA 2016, 113, 1949-1954. [CrossRef] [PubMed]

54. Verma, R.K.; Santosh Kumar, V.V.; Yadav, S.K.; Pushkar, S.; Rao, M.V.; Chinnusamy, V. Overexpression of ABA Receptor PYL10 gene confers drought and cold tolerance to indica rice. Front. Plant Sci. 2019, 10, 1488. [CrossRef] [PubMed]

55. Zou, M.; Guan, Y.; Ren, H.; Zhang, F.; Chen, F. A bZIP transcription factor, OsABI5, is involved in rice fertility and stress tolerance. Plant Mol. Biol. 2008, 66, 675-683. [CrossRef] [PubMed]

56. Wind, J.J.; Peviani, A.; Snel, B.; Hanson, J.; Smeekens, S.C. ABI4: Versatile activator and repressor. Trends Plant Sci. 2013, 18, 125-132. [CrossRef] [PubMed]

57. Kang, J.; Hwang, J.U.; Lee, M.; Kim, Y.Y.; Assmann, S.M.; Martinoia, E.; Lee, Y. PDR-type ABC transporter mediates cellular uptake of the phytohormone abscisic acid. Proc. Natl. Acad. Sci. USA 2010, 107, 2355-2360. [CrossRef] [PubMed]

58. Inoue, S.I.; Kinoshita, T. Blue light regulation of stomatal opening and the plasma membrane H+-ATPase. Plant Physiol. 2017, 174, 531-538. [CrossRef]

59. Schachtman, D.P.; Schroeder, J.I.; Lucas, W.J.; Anderson, J.A.; Gaber, R.F. Expression of an inward-rectifying potassium channel by the Arabidopsis KAT1 cDNA. Science 1992, 258, 1654-1658. [CrossRef]

60. Pilot, G.; Lacombe, B.; Gaymard, F.; Chérel, I.; Boucherez, J.; Thibaud, J.B.; Sentenac, H. Guard Cell Inward $\mathrm{K}+$ Channel Activity in Arabidopsis Involves Expression of the Twin Channel Subunits KAT1 and KAT2. J. Biol. Chem. 2001, 276, 3215-3221. [CrossRef]

61. Takemiya, A.; Sugiyama, N.; Fujimoto, H.; Tsutsumi, T.; Yamauchi, S.; Hiyama, A.; Shimazaki, K.I. Phosphorylation of BLUS1 kinase by phototropins is a primary step in stomatal opening. Nat. Commun. 2013, 4, 1-8. [CrossRef]

62. Kong, S.G.; Suetsugu, N.; Kikuchi, S.; Nakai, M.; Nagatani, A.; Wada, M. Both phototropin 1 and 2 localize on the chloroplast outer membrane with distinct localization activity. Plant Cell Physiol. 2013, 54, 80-92. [CrossRef] [PubMed]

63. Briggs, W.R.; Christie, J.M. Phototropins 1 and 2: Versatile plant blue-light receptors. Trends Plant Sci. 2002, 7, 204-210. [CrossRef] 
64. Cho, H.Y.; Tseng, T.S.; Kaiserli, E.; Sullivan, S.; Christie, J.M.; Briggs, W.R. Physiological roles of the light, oxygen, or voltage domains of phototropin 1 and phototropin 2 in Arabidopsis. Plant Physiol. 2007, 143, 517-529. [CrossRef] [PubMed]

65. Hart, J.E.; Sullivan, S.; Hermanowicz, P.; Petersen, J.; Diaz-Ramos, L.A.; Hoey, D.J.; Christie, J.M. Engineering the phototropin photocycle improves photoreceptor performance and plant biomass production. Proc. Natl. Acad. Sci. USA 2019, 116, 12550-12557. [CrossRef]

66. Aihara, Y.; Tabata, R.; Suzuki, T.; Shimazaki, K.I.; Nagatani, A. Molecular basis of the functional specificities of phototropin 1 and 2. Plant J. 2008, 56, 364-375. [CrossRef]

67. Takemiya, A.; Shimazaki, K.I. Arabidopsis phot1 and phot2 phosphorylate BLUS1 kinase with different efficiencies in stomatal opening. J. Plant Res. 2016, 129, 167-174. [CrossRef]

68. Estill, K.; Delaney, R.H.; Smith, W.K.; Ditterline, R.L. Water relations and productivity of alfalfa leaf chlorophyll variants. Crop Sci. 1991, 31, 1229-1233. [CrossRef]

69. Ashraf, M.; Ahmad, A.; McNeilly, T. Growth and photosynthetic characteristics in pearl millet under water stress and different potassium supply. Photosynthetica 2001, 39, 389-394. [CrossRef]

70. Zhang, B.; Liu, C.; Wang, Y.; Yao, X.; Wang, F.; Wu, J.; Liu, K. Disruption of a carotenoid cleavage dioxygenase 4 gene converts flower colour from white to yellow in Brassica species. New Phytol. 2015, 206, 1513-1526. [CrossRef]

71. Kang, Y.R.; Park, J.; Jung, S.K.; Chang, Y.H. Synthesis, characterization, and functional properties of chlorophylls, pheophytins, and Zn-pheophytins. Food Chem. 2018, 245, 943-950. [CrossRef]

72. Shalygo, N.; Czarnecki, O.; Peter, E.; Grimm, B. Expression of chlorophyll synthase is also involved in feedback-control of chlorophyll biosynthesis. Plant Mol. Biol. 2009, 71, 425. [CrossRef] [PubMed]

73. Wang, X.; Liu, L. Crystal structure and catalytic mechanism of 7-hydroxymethyl chlorophyll a reductase. J. Biol. Chem. 2016, 291, 13349-13359. [CrossRef] [PubMed]

74. Ito, H.; Ohtsuka, T.; Tanaka, A. Conversion of chlorophyll b to chlorophyll a via 7-hydroxymethyl chlorophyll. J. Biol. Chem. 1996, 271, 1475-1479. [CrossRef] [PubMed]

75. Meguro, M.; Ito, H.; Takabayashi, A.; Tanaka, R.; Tanaka, A. Identification of the 7-hydroxymethyl chlorophyll a reductase of the chlorophyll cycle in Arabidopsis. Plant Cell 2011, 23, 3442-3453. [CrossRef] [PubMed]

76. Sakuraba, Y.; Kim, Y.S.; Yoo, S.C.; Hörtensteiner, S.; Paek, N.C. 7-Hydroxymethyl chlorophyll a reductase functions in metabolic channeling of chlorophyll breakdown intermediates during leaf senescence. Biochem. Biophys. Res. Commun. 2013, 430, 32-37. [CrossRef] [PubMed]

77. Piao, W.; Han, S.H.; Sakuraba, Y.; Paek, N.C. Rice 7-hydroxymethyl chlorophyll a reductase is involved in the promotion of chlorophyll degradation and modulates cell death signaling. Mol. Cells 2017, 40, 773.

78. Jaleel, C.A.; Manivannan, P.; Wahid, A.; Farooq, M.; Al-Juburi, H.J.; Somasundaram, R.; Panneerselvam, R. Drought stress in plants: A review on morphological characteristics and pigments composition. Int. J. Agric. Biol. 2009, 11, 100-105.

79. Ashraf, M.H.; Harris, P.J. Photosynthesis under stressful environments: An overview. Photosynthetica 2013, 51, 163-190. [CrossRef]

80. Zhang, C.; Zhang, W.; Ren, G.; Li, D.; Cahoon, R.E.; Chen, M.; Cahoon, E.B. Chlorophyll synthase under epigenetic surveillance is critical for vitamin E synthesis, and altered expression affects tocopherol levels in Arabidopsis. Plant Physiol. 2015, 168, 1503-1511. [CrossRef]

81. Jia, K.P.; Baz, L.; Al-Babili, S. From carotenoids to strigolactones. J. Exp. Bot. 2018, 69, 2189-2204. [CrossRef]

82. Wang, Y.; Bouwmeester, H.J. Structural diversity in the strigolactones. J. Exp. Bot. 2018, 69, $2219-2230$. [CrossRef] [PubMed]

83. Ruiz-Lozano, J.M.; Aroca, R.; Zamarreño, Á.M.; Molina, S.; Andreo-Jiménez, B.; Porcel, R.; López-Ráez, J.A. Arbuscular mycorrhizal symbiosis induces strigolactone biosynthesis under drought and improves drought tolerance in lettuce and tomato. Plant Cell Environ. 2016, 39, 441-452. [CrossRef] [PubMed]

84. Min, Z.; Li, R.; Chen, L.; Zhang, Y.; Li, Z.; Liu, M.; Fang, Y. Alleviation of drought stress in grapevine by foliar-applied strigolactones. Plant Physiol. Biochem. 2019, 135, 99-110. [CrossRef] [PubMed]

85. Gao, J.; Zhang, T.; Xu, B.; Jia, L.; Xiao, B.; Liu, H.; Xia, Q. CRISPR/Cas9-mediated mutagenesis of carotenoid cleavage dioxygenase 8 (CCD8) in tobacco affects shoot and root architecture. Int. J. Mol. Sci. 2018, 19, 1062. [CrossRef] [PubMed] 
86. Bari, V.K.; Nassar, J.A.; Kheredin, S.M.; Gal-On, A.; Ron, M.; Britt, A.; Aly, R. CRISPR/Cas9-mediated mutagenesis of carotenoid cleavage dioxygenase 8 in tomato provides resistance against the parasitic weed Phelipanche aegyptiaca. Sci. Rep. 2019, 9,1-12. [CrossRef]

87. Ren, C.; Guo, Y.; Kong, J.; Lecourieux, F.; Dai, Z.; Li, S.; Liang, Z. Knockout of VvCCD8 gene in grapevine affects shoot branching. BMC Plant Biol. 2020, 20,1-8. [CrossRef]

88. Chaves, M.M.; Flexas, J.; Pinheiro, C. Photosynthesis under drought and salt stress: Regulation mechanisms from whole plant to cell. Ann. Bot. 2009, 103, 551-560. [CrossRef]

89. Portis, A.R. Rubisco activase-Rubisco's catalytic chaperone. Photosynth. Res. 2003, 75, 11-27. [CrossRef]

90. Perdomo, J.A.; Capó-Bauçà, S.; Carmo-Silva, E.; Galmés, J. Rubisco and rubisco activase play an important role in the biochemical limitations of photosynthesis in rice, wheat, and maize under high temperature and water deficit. Front. Plant Sci. 2017, 8, 490. [CrossRef]

91. Feiz, L.; Williams-Carrier, R.; Wostrikoff, K.; Belcher, S.; Barkan, A.; Stern, D.B. Ribulose-1, 5-bis-phosphate carboxylase/oxygenase accumulation factor1 is required for holoenzyme assembly in maize. Plant Cell 2012, 24, 3435-3446. [CrossRef]

92. Vitlin Gruber, A.; Feiz, L. Rubisco assembly in the chloroplast. Front. Mol. Biosci. 2018, 5, 24. [CrossRef] [PubMed]

93. Hauser, T.; Bhat, J.Y.; Miličić, G.; Wendler, P.; Hartl FUBracher, A.; Hayer-Hartl, M. Structure and mechanism of the Rubisco-assembly chaperone Raf1. Nat. Struct. Mol. Biol. 2015, 22, 720-728. [CrossRef] [PubMed]

(C) 2020 by the authors. Licensee MDPI, Basel, Switzerland. This article is an open access article distributed under the terms and conditions of the Creative Commons Attribution (CC BY) license (http://creativecommons.org/licenses/by/4.0/). 